Cochrane Database of Systematic Reviews

\title{
Bilateral versus unilateral hearing aids for bilateral hearing impairment in adults (Review)
}

Schilder AGM, Chong LY, Ftouh S, Burton MJ

Schilder AGM, Chong LY, Ftouh S, Burton MJ.

Bilateral versus unilateral hearing aids for bilateral hearing impairment in adults.

Cochrane Database of Systematic Reviews 2017, Issue 12. Art. No.: CD012665.

DOI: 10.1002/14651858.CD012665.pub2.

www.cochranelibrary.com 
TABLE OF CONTENTS

HEADER 1

ABSTRACT

PLAIN LANGUAGE SUMMARY

SUMMARY OF FINDINGS

BACKGROUND

OBJECTIVES

METHODS

RESULTS

Figure 1.

Figure 2.

Figure 3.

DISCUSSION

AUTHORS' CONCLUSIONS

ACKNOWLEDGEMENTS

REFERENCES

CHARACTERISTICS OF STUDIES

APPENDICES

CONTRIBUTIONS OF AUTHORS

DECLARATIONS OF INTEREST

SOURCES OF SUPPORT

DIFFERENCES BETWEEN PROTOCOL AND REVIEW

INDEX TERMS 
[Intervention Review]

\section{Bilateral versus unilateral hearing aids for bilateral hearing impairment in adults}

Anne GM Schilder' ${ }^{1}$, Lee Yee Chong 2 , Saoussen Ftouh ${ }^{3}$, Martin J Burton²

1evidENT, Ear Institute, Faculty of Brain Sciences, University College London, London, UK. 2UK Cochrane Centre, Oxford, UK. ${ }^{\text {NNational }}$ Guideline Centre, London, UK

Contact address: Anne GM Schilder, evidENT, Ear Institute, Faculty of Brain Sciences, University College London, 330 Grays Inn Road, London, WC1X 8DA, UK. a.schilder@ucl.ac.uk.

Editorial group: Cochrane ENT Group.

Publication status and date: New, published in Issue 12, 2017.

Citation: Schilder AGM, Chong LY, Ftouh S, Burton MJ. Bilateral versus unilateral hearing aids for bilateral hearing impairment in adults. Cochrane Database of Systematic Reviews 2017, Issue 12. Art. No.: CD012665. DOI: 10.1002/14651858.CD012665.pub2.

Copyright (c) 2017 The Cochrane Collaboration. Published by John Wiley \& Sons, Ltd.

\section{A B S T R A C T}

\section{Background}

Acquired hearing loss is common and its incidence increases markedly with age. In most people, 'age-related' hearing loss is sensorineural (due to the loss of cochlear hair cells) and bilateral, affecting both ears to the same degree. Hearing loss categorised as mild, moderate or severe is primarily managed with hearing aids. People with bilateral hearing loss may be offered one aid, fitted to one specific ear, or two aids fitted to both ears. There is uncertainty about the relative benefits to people with hearing loss of these different strategies.

\section{Objectives}

To assess the effects of bilateral versus unilateral hearing aids in adults with a bilateral hearing impairment.

\section{Search methods}

The Cochrane ENT Information Specialist searched the ENT Trials Register; Cochrane Register of Studies Online; PubMed; Ovid Embase; CINAHL; Web of Science; ClinicalTrials.gov; ICTRP and additional sources for published and unpublished trials. The date of the search was 8 June 2017.

\section{Selection criteria}

Randomised controlled trials (RCTs) comparing the fitting of two versus one ear-level acoustic hearing aids in adults (over 18 years) with a bilateral hearing impairment, both ears being eligible for hearing aids.

\section{Data collection and analysis}

We used the standard methodological procedures expected by Cochrane. Our primary outcomes were patient preference for bilateral or unilateral aids, hearing-specific health-related quality of life and adverse effects (pain or discomfort in the ear, initiation or exacerbation of middle or outer ear infection). Secondary outcomes included: usage of hearing aids (as measured by, for example, data logging or battery consumption), generic health-related quality of life, listening ability and audiometric benefit measured as binaural loudness summation. We used GRADE to assess the quality of the evidence for each outcome; this is indicated in italics.

\section{Main results}

We included four cross-over RCTs with a total of 209 participants, ranging in age from 23 to 85 and with a preponderance of men. All the studies allowed the use of hearing aids for a total period of at least eight weeks before questions on preference were asked. All studies recruited patients with bilateral hearing loss but there was considerable variation in the types and degree of sensorineural hearing loss that the participants were experiencing. 
Three of the studies were published before the mid-1990s whereas the fourth study was published in 2011. Therefore, only the most recent study used hearing aids incorporating technology comparable to that currently readily available in high-income settings. Of the four studies, two were conducted in the UK in National Health Service (NHS - public sector) patients: one recruited patients from primary care with hearing loss detected by a screening programme whereas the other recruited patients who had been referred by their primary care practitioner to an otolaryngology department for hearing aids. The other two studies were conducted in the United States: one study recruited only military personnel or veterans with noise-induced hearing loss whereas about half of the participants in the other study were veterans.

Only one primary outcome (patient preference) was reported in all studies. The percentage of patients who preferred bilateral hearing aids varied between studies: this was $54 \%$ ( 51 out of 94 participants), $39 \%$ ( 22 out of 56 ), $55 \%$ (16 out of 29 ) and $77 \%$ ( 23 out of 30 ), respectively. We have not combined the data from these four studies. The evidence for this outcome is of very low quality.

The other outcomes of interest were not reported in the included studies.

\section{Authors' conclusions}

This review identified only four studies comparing the use of one hearing aid with two. The studies were small and included participants of widely varying ages. There was also considerable variation in the types and degree of sensorineural hearing loss that the participants were experiencing.

For the most part, the types of hearing aid evaluated would now be regarded, in high-income settings, as 'old technology', with only one study looking at 'modern' digital aids. However, the relevance of this is uncertain, as this review did not evaluate the differences in outcomes between the different types of technology.

We were unable to pool data from the four studies and the very low quality of the evidence leads us to conclude that we do not know if people with hearing loss have a preference for one aid or two. Similarly, we do not know if hearing-specific health-related quality of life, or any of our other outcomes, are better with bilateral or unilateral aids.

\section{PLAIN LANGUAGE SUMMARY}

Bilateral (two) versus unilateral (one) hearing aid(s) for bilateral hearing impairment in adults

\section{Review question}

Should adult patients with bilateral (two-sided) hearing loss be fitted with one or two hearing aids?

\section{Background}

Hearing loss can be present from birth or can come on in later life. The latter is called 'acquired' hearing loss and is common. Its incidence increases markedly with age. In most people, 'age-related' hearing loss is due to the loss of cells in the inner ear (so called 'sensorineural hearing loss') and affects both ears to the same degree. Hearing loss categorised as mild, moderate or severe is primarily managed with hearing aids. People with bilateral hearing loss may be offered one aid, fitted to one specific ear, or two aids fitted to both ears. There is uncertainty about the relative benefits to patients of these different strategies.

\section{Study characteristics}

We included four studies with a total of 209 patients, ranging in age from 23 to 85 and with more men than women. All the studies allowed the use of hearing aids for a total period of at least eight weeks before questions were asked about their preference for one or two aids. In all the studies the patients had bilateral hearing loss but there was considerable variation in what type of hearing loss they suffered from and how bad their hearing was.

Three of the studies were published before the mid-1990s and the fourth study was published in 2011 . Therefore, only the most recent study used 'modern' hearing aids similar to those that are widely available in high-income countries. Of the four studies, two were conducted in the UK in National Health Service (NHS - public sector) patients. One of these looked at patients from primary care whose hearing loss had been picked up by a screening programme. The other looked at patients whose primary care practitioner thought they might benefit from hearing aids so had referred them to the local ENT department to get them. The other two studies were conducted in the United States: one study recruited only people on active military duty, or who had served in the military and had hearing loss due to being exposed to loud noises. About half of the people in the other study were ex-military.

\section{Key results and quality of the evidence}

Only one of the outcomes we thought was most important - patient preference - was reported in all studies. The percentage of patients who preferred two hearing aids to one varied between studies: this was $54 \%$ ( 51 out of 94 ), $39 \%$ ( 22 out of 56 ), $55 \%$ (16 out of 29 ) and $77 \%$ (23 out of 30 ), respectively. We did not combine the numbers from these four studies because it would not have been right to do so. We 
graded the quality of evidence for this outcome as very low on a scale that goes high - medium - low - very low. There was no information in the four studies on the other outcomes we were interested in.

\section{Conclusions}

This review identified only four studies comparing the use of one hearing aid with two. The studies were small and included people of widely varying ages. There was also considerable variation in the types of their deafness and in how deaf they were.

For the most part, the types of hearing aid evaluated would now be regarded, in high-income countries, as 'old technology', with only one study looking at 'modern' digital aids. However, we do not know if this is relevant or not. This review did not look at the differences between other 'old' and 'new' types of hearing aid.

We could not combine the numbers from the four studies. Overall, this fact and the very low quality of the evidence leads us to conclude that we do not know if patients have a preference for one aid or two. Similarly, we do not know if a patient's quality of life is better with one or two aids. 


\section{SUMMARY OF FINDINGS}

\section{Summary of findings for the main comparison. Bilateral versus unilateral hearing aids for hearing loss in adults}

\section{Bilateral versus unilateral hearing aids for hearing loss in adults}

Patient or population: adults with hearing loss

Settings: any setting with first-time users of hearing aids

Intervention: bilateral hearing aids

Comparison: unilateral hearing aids

\begin{tabular}{|c|c|c|c|c|}
\hline \multirow[t]{2}{*}{ Outcomes } & \multicolumn{2}{|c|}{ Anticipated absolute effects ${ }^{\star}(95 \% \mathrm{Cl})$} & \multirow{2}{*}{$\begin{array}{l}\text { Quality of the } \\
\text { evidence } \\
\text { (GRADE) }\end{array}$} & \multirow[t]{2}{*}{ What happens } \\
\hline & $\begin{array}{l}\text { With unilateral } \\
\text { hearing aids }\end{array}$ & $\begin{array}{l}\text { With bilateral } \\
\text { hearing aids }\end{array}$ & & \\
\hline $\begin{array}{l}\text { Patient preference } \\
\text { № of participants: } 178 \text { ( } 4 \\
\text { RCTs) } \\
\text { Total of } 8 \text { to } 12 \text { weeks } \\
\text { follow-up; } 1 \text { day to } 10 \\
\text { weeks per phase }\end{array}$ & \multicolumn{2}{|c|}{$\begin{array}{l}\text { Preference for bilateral hearing aids } \\
\text { Study } 1 \text { (2011): } 54 \%(51 / 94) \text { - cross-over, } \\
\text { 2:1 randomised to unilateral } \\
\text { Study } 2 \text { (1993): } 39 \%(22 / 56) \text { - cross-over, } \\
\text { 2:1 randomised to unilateral (all chose } \\
\text { unilateral at baseline) } \\
\text { Study } 3 \text { (1991): } 55 \%(16 / 29) \text { - cross-over } \\
\text { Study } 4 \text { (1981): } 77 \%(23 / 30) \text { - cross-over } \\
\text { (all military personnel) }\end{array}$} & $\begin{array}{l}\oplus \ominus \ominus \ominus \\
\text { very low } 1,2,3\end{array}$ & $\begin{array}{l}\text { There was insufficient information to } \\
\text { determine whether most patients prefer } \\
\text { unilateral or bilateral hearing aids; we } \\
\text { cannot conclude which is preferable. }\end{array}$ \\
\hline Hearing-specific HRQL & \multicolumn{4}{|c|}{$\begin{array}{l}\text { None of the studies measured and reported this outcome in a way that allowed comparison between the } \\
\text { two interventions. }\end{array}$} \\
\hline $\begin{array}{l}\text { Adverse effects: pain or } \\
\text { discomfort in the ear, ini- } \\
\text { tiation or exacerbation of } \\
\text { middle or outer ear infec- } \\
\text { tion }\end{array}$ & \multicolumn{4}{|c|}{ None of the studies reported the collection of adverse event data. } \\
\hline $\begin{array}{l}\text { Usage of hearing aids (in- } \\
\text { cluding data logging and } \\
\text { self-report) } \\
\text { № of participants: } 56 \text { (1 } \\
\text { study) } \\
10 \text { weeks }\end{array}$ & $\begin{array}{l}\text { "often or all the } \\
\text { time": } 84 \% \text { of } \\
\text { responses in } \\
\text { monaural hearing } \\
\text { aid phase }\end{array}$ & $\begin{array}{l}\text { "often or all the } \\
\text { time": } 28 \% \text { of re- } \\
\text { sponses }\end{array}$ & $\begin{array}{l}\oplus \ominus \Theta \odot \\
\text { very low } 1,2,3\end{array}$ & $\begin{array}{l}\text { Although one study reported a higher } \\
\text { percentage of people using the hear- } \\
\text { ing aid "often or all the time" when bin- } \\
\text { aurally aided, we still cannot conclude } \\
\text { whether people will use their hearing } \\
\text { aids more often when fitted bilateral- } \\
\text { ly or unilaterally; the evidence has very } \\
\text { high uncertainty levels. }\end{array}$ \\
\hline
\end{tabular}

Generic HRQL - not mea- None of the studies reported using these measures.

sured

Listening ability

None of the studies measured and reported this outcome in a way that allowed comparison between the two interventions.

Sound localisation as measured by (non-validated) questionnaire

$\begin{array}{ll}\text { "better when } & \text { "18\% found lo- } \\ \text { monoaurally aid- } & \text { calization worse } \\ \text { ed" } & \text { when binaurally }\end{array}$

$\oplus \ominus \ominus \ominus$ very low $1,2,3$
Very little information was provided by a study that used a non-validated method to measure sound localisation. We can- 


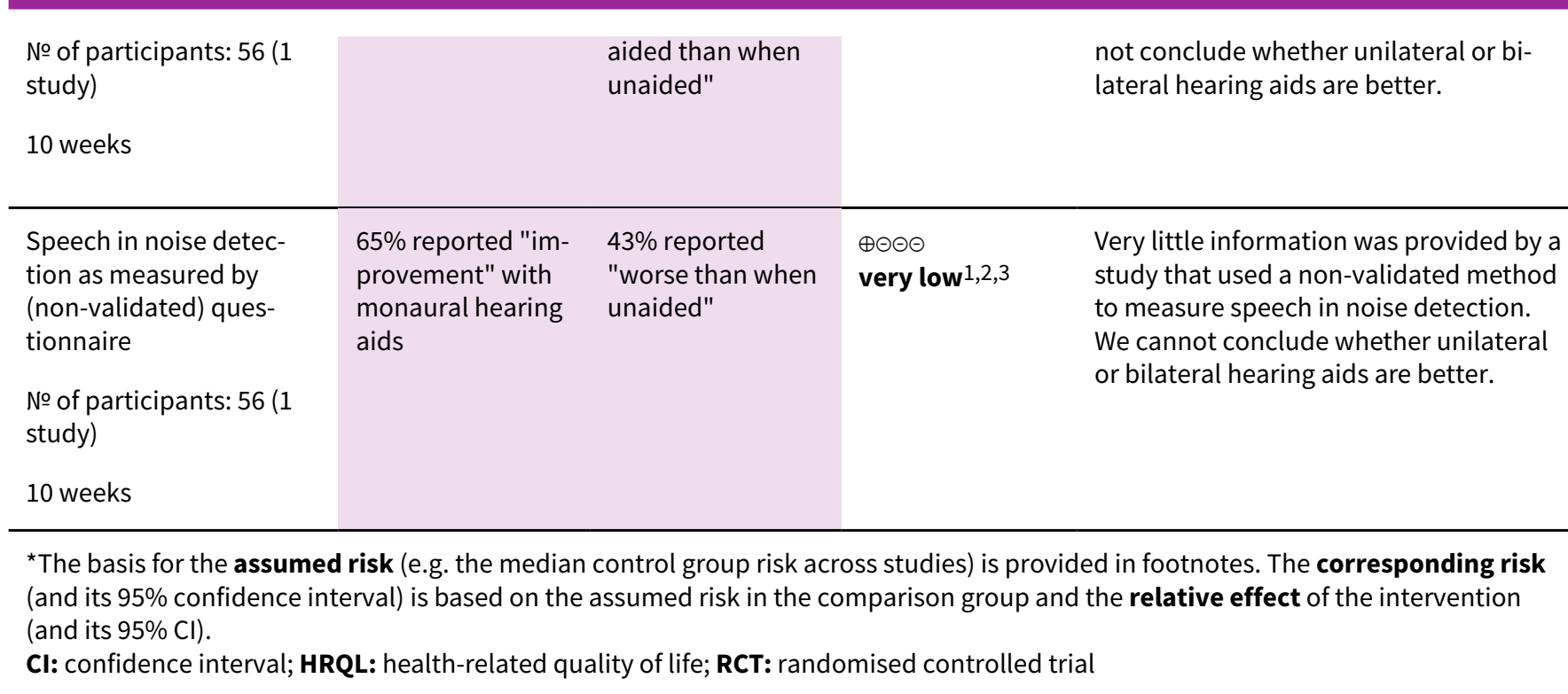

GRADE Working Group grades of evidence

High quality: Further research is very unlikely to change our confidence in the estimate of effect.

Moderate quality: Further research is likely to have an important impact on our confidence in the estimate of effect and may change the estimate.

Low quality: Further research is very likely to have an important impact on our confidence in the estimate of effect and is likely to change the estimate.

Very low quality: We are very uncertain about the estimate.

1There is a serious risk of bias for all studies due to the randomisation methods used and lack of blinding. All studies were cross-over trials and in two studies twice as many patients were randomised to the unilateral intervention arms than the bilateral arms (2:1 proportion). In addition, most participants in one study had no experience of hearing aids but chose unilateral hearing aids when given a choice at the start of the study, which may indicate a preference for unilateral aids before the start of the trial.

2There is a serious risk of indirectness for three reasons: 1) Three of the studies were conducted more than 20 years ago; the type of hearing aids available then may be different from now and patients' perception and acceptance of hearing aids may have changed. 2) Military personnel/veterans were the only participants in one of the studies and made up more than half of the participants in another study. 3) One of the studies had a one-week trial phase while another had a one-hour to three-day trial phase before a longer trial period where hearing aids were used as preferred. Another study provided a phase of four to six weeks in each configuration. These periods may not be sufficient to fully test the aids in a specific configuration.

3There is serious imprecision for any data reported due to the very small sample sizes available. 


\section{B A C K G R O U N D}

\section{Description of the condition}

Acquired hearing loss is common and has been identified as a key public health priority by the World Health Organization (WHO). The incidence increases markedly with age and, with an ageing population, it is estimated that by 2030 it will affect one in five people and be in the top 10 of disease burdens in the UK. Hearing loss has also been identified as an important risk factor for dementia (Livingston 2017).

In most people, 'age-related' hearing loss is sensorineural (due to the loss of cochlear hair cells) and bilateral, affecting both ears to the same degree. Hearing loss can be categorised as 'mild', 'moderate' or 'severe' and is primarily managed with hearing aids. People with bilateral hearing loss may be offered one aid, fitted to one specific ear, or two aids fitted to both ears. There is uncertainty about the relative benefits to patients of these different strategies.

Hearing is routinely assessed by pure-tone audiometry. The level of disability caused by hearing loss is mainly determined by the hearing in the better hearing ear. Using the audiogram and calculating the average of the thresholds of detection at four frequencies $(0.5 \mathrm{kHz}, 1 \mathrm{kHz}, 2 \mathrm{kHz}$ and $4 \mathrm{kHz})$ hearing may be categorised into 'normal' hearing ( 0 to $20 \mathrm{~dB} \mathrm{HL}$ ), 'mild' hearing loss (21 to $40 \mathrm{~dB} \mathrm{HL}$ ), 'moderate' hearing loss ( 41 to $70 \mathrm{~dB} \mathrm{HL}$ ), 'severe' hearing loss (71 to $95 \mathrm{~dB} \mathrm{HL}$ ) and 'profound' hearing loss (> $90 \mathrm{~dB}$ HL) (WHO 1991).

Patients with a mild or moderate sensorineural hearing loss are primarily managed with hearing aids; for those with severe or profound hearing loss cochlear implants are available.

\section{Description of the intervention}

\section{Hearing aids}

Hearing aids amplify the sound reaching the ear. They can use either digital or analogue technology. With either type, the degree of amplification can be adjusted to suit the characteristics of the patient's hearing loss. Hearing aids can vary in design and in where they are positioned: in-the-canal, in-the-ear, behind-theear and body-worn. The degree of hearing impairment, patient choice and cost may all determine which is used. There is considerable variation in patients' listening requirements. Some require amplification only at certain times; for example, when listening to the television. Others need amplification in more challenging situations, such as when in groups, conversing in the presence of background noise.

Hearing aids are often offered to patients with mild to moderate hearing loss (Ferguson 2017); when the hearing loss is more severe alternative options such as cochlear implants may be offered. Those who use hearing aids - or their carers - need sufficient manual dexterity to position the aid in the ear, to switch it on, to maintain it (for example, clean it and change the batteries) and, for some hearing aids, to make program button and/or volume control changes. This may pose a challenge to many people.

Amplification does not produce 'normal' hearing. In people with normal hearing, sound is detected and processed by the ear, and impulses then travel to the brain to be further processed and interpreted. Patients with sensorineural hearing loss often have problems not only with sound detection but also with processing and interpretation to some degree. As a result, when the output that a hearing aid produces is presented to the auditory system and interpreted by the brain, the results will not be the same as when these pathways are functioning normally. This is one reason why some hearing aid users find aiding beneficial and some do not, and why many people have difficulty in the presence of background noise. In the normally hearing person, the auditory system has an amazing capacity to discriminate speech in noise. This is ability is not restored to normal when people with sensorineural hearing loss use a hearing aid (Dillon 2012).

\section{How the intervention might work}

\section{Bilateral hearing aids}

In normal hearing people, there is general benefit in having two ears rather than one: binaural hearing enables the listener to determine from which side the sound is coming (lateralisation). This is more difficult when hearing is reduced or absent in one ear.

In the light of this, it is easy to assume that patients with binaural hearing aids will be able to function more 'normally' than those who wear only one aid. However, this may not be the case.

Possible benefits of bilateral hearing aids include:

- An improved ability to localise sound.

- So-called 'binaural loudness summation'. This is a psychophysical phenomenon in which a sound presented to both ears is perceived to be louder than if the same sound were only presented to one ear. This can be advantageous in some listening situations.

- The assurance of 'better-ear listening'. In some situations, one of the ears will be presented with a clearer signal of interest than the other (for example, when a sound is coming from the side). In theory, this is helpful in some day-to-day listening situations.

- Some patients with hearing loss also suffer from ear infections that may get worse when wearing a hearing aid. This can result in them having to leave a hearing aid out of the affected ear for a period of time. Having bilateral aids gives them the option to hearing use aids in one or both ears as circumstances dictate.

Possible disadvantages of bilateral hearing aids include:

- Cost.

- Simplicity. One aid may be easier to use than two.

- So-called 'binaural interference'. The patient finds it more difficult to understand speech when receiving amplified inputs in both ears at the same time.

When two hearing aids are being considered, there are at least two alternative approaches:

- fit one hearing aid initially and consider an aid for the other ear later;

- fit two aids from the beginning and leave it to the patient to use two or one.

These fitting strategies may have one of several consequences:

- satisfaction and continued use of one or both aids;

- abandonment of the use of one or both hearing aids altogether; 
- continued use of one aid but abandonment of the second; or

- a desire to try a second aid by those fitted with only one.

The provision of hearing aids varies widely in different health services and resource settings. In some countries hearing aids (either one or two) are provided 'free' to the patient, funded by the local health care providers. In others, hearing aids are only available to those who can pay for them. In both systems, there are cost implications when two hearing aids are provided rather than one.

\section{Why it is important to do this review}

The current existence of two main strategies for fitting hearing aids for patients with bilateral hearing loss (bilateral versus unilateral hearing aids) has arisen due to two main factors: uncertainty about the magnitude of the benefit of a second aid, and the additional cost of providing two aids. This prevents the necessary cost-effectiveness analysis being undertaken.

Evidence from randomised controlled trials on the relative effectiveness of bilateral versus unilateral fitting is important to guide practice. We have not identified any previous systematic review therefore a Cochrane Review to evaluate the effects of bilateral versus unilateral hearing aids for bilateral hearing impairment is warranted.

\section{O B JECTIVES}

To assess the effects of bilateral versus unilateral hearing aids in adults with a bilateral hearing impairment.

\section{MET HOD S}

\section{Criteria for considering studies for this review}

\section{Types of studies}

Randomised controlled trials (RCTs). This included:

- parallel-group study designs, where patients are randomised to unilateral or bilateral aids; or

- cross-over study designs for the order of fitting of unilateral/ bilateral aids for each patient; or

- cluster-randomised trials, where randomisation is done by practice or setting (the number of randomised groups must be more than two);

- quasi-randomised trials, because only a small number of trials was expected.

\section{Types of participants}

We included studies if the participants met the following criteria:

- adults (over 18 years);

- with a bilateral hearing impairment and both ears suitable for hearing aids.

We excluded studies from the review if a majority of the participants had one or more of the following characteristics:

- although asymmetric hearing impairment was not excluded, if a patient has one ear that is audiometrically normal or one ear that has a profound or total loss conventional hearing aids are not appropriate for them.

\section{Types of interventions}

The comparison of interest was:

- fitting of two versus one ear-level acoustic hearing aids.

We excluded implants, body-worn aids and bone-conduction hearing aids.

We applied no minimum duration of use or follow-up as an inclusion criterion, but we considered these as part of the GRADE evidence evaluation for indirectness of evidence.

\section{Types of outcome measures}

We analysed the following outcomes in the review, but we did not use them as a basis for including or excluding studies.

\section{Primary outcomes}

- Patient preference for bilateral versus unilateral aids.

- Hearing-specific health-related quality of life (e.g. Hearing Handicap Inventory for the Elderly (HHIE), Hearing Handicap Inventory for Adults (HHIA), Auditory Disability Preference Visual Analogue Scale (ADPI-VAS), Quantified Denver Scale of communication (QDS).

- Adverse effects (pain or discomfort in the ear, initiation or exacerbation of middle or outer ear infection).

\section{Secondary outcomes}

- Usage of hearing aids (e.g. data logging, battery consumption) for the duration of the trial (Laplante-Levesque 2014).

- Generic health-related quality of life (Health Utilities Index Mark 3 (HUI-3), the Glasgow Benefit Inventory (GBI), EQ-5D, SF-36, the World Health Organization (WHO) Disability Assessment Schedule (WHO-DAS), Self Evaluation of Life Function (SELF).

- Listening ability (e.g. Abbreviated Profile of Hearing Aid Benefit (APHAB), Speech, Spatial and Qualities of Hearing Scale (SSQ), Glasgow Hearing Aid Benefit profile), Device Orientated Subjective Outcome Scale (DOSO).

- Audiometric benefit measured as binaural loudness summation.

- Outcome reported by carer or 'communication partner' (Note 1).

- Annoyance, measured using patient-reported outcome measures (Note 1).

- Sound localisation as measured by laboratory tests (Note 1).

- Speech in noise detection as measured by laboratory tests (Note 1).

Note 1: These additional outcomes were included as part of a collaboration with a National Institute for Health and Care Excellence (NICE) guideline committee.

\section{Search methods for identification of studies}

The Cochrane ENT Information Specialist, in conjunction with the NICE Information Specialist, conducted systematic searches for randomised controlled trials and controlled clinical trials. There were no language, publication year or publication status restrictions. The date of the search was 8 June 2017.

\section{Electronic searches}

The Information Specialist searched: 
- the Cochrane Register of Studies ENT Trials Register (searched 8 June 2017);

- the Cochrane Register for of Studies Online (searched 8 June 2017);

- Ovid MEDLINE(R) Epub Ahead of Print, In-Process \& Other NonIndexed Citations, Ovid MEDLINE(R) Daily and Ovid MEDLINE(R) (1946 to 8 June 2017);

- Ovid EMBASE (1974 to 8 June 2017);

- EBSCO CINAHL (1982 to 8 June 2017);

- LILACS (searched 8 June 2017);

- KoreaMed (searched 8 June 2017);

- Web of Knowledge, Web of Science (1945 to 8 June 2017);

- ClinicalTrials.gov, www.clinicaltrials.gov (search via the Cochrane Register of Studies 8 June 2017);

- World Health Organization (WHO) International Clinical Trials Registry Platform (ICTRP) (searched 8 June 2017).

The Information Specialist modelled subject strategies for databases on the search strategy designed for Ovid MEDLINE and Ovid Embase. Where appropriate, they were combined with subject strategy adaptations of the highly sensitive search strategy designed by Cochrane for identifying randomised controlled trials and controlled clinical trials (as described in the Cochrane Handbook for Systematic Reviews of Interventions Version 5.1.0, Box 6.4.b. (Handbook 2011). Search strategies for major databases including CENTRAL are provided in Appendix 1.

\section{Searching other resources}

We scanned the reference lists of identified publications for additional trials and contacted trial authors where necessary. In addition, the Information Specialist searched Ovid MEDLINE to retrieve existing systematic reviews relevant to this review, so that we could scan their reference lists for additional trials, and also ran non-systematic searches of Google Scholar to retrieve grey literature and other sources of potential trials. In addition, the Information Specialist carried out forward citation searches using Web of Knowledge, Web of Science (1945 to 8 June 2017) for papers citing Cox 2011 and Stephens 1991 so that we could scan these references for additional trials.

\section{Data collection and analysis}

\section{Selection of studies}

Two authors (SF, LYC) independently screened the titles and abstracts of the papers found by the searches against the criteria for inclusion. We then retrieved and independently reviewed the full text of the potentially eligible papers to determine whether they met the inclusion criteria for the review. We resolved any differences by discussion and consensus, with the involvement of a third author for clinical or methodological input.

\section{Data extraction and management}

Two authors (SF, LYC) independently extracted the data from each study using a standardised data extraction form (Appendix 2). We tried to identify multiple publications for included studies and, if a study had more than one publication, we retrieved all publications to ensure complete extraction of data. If we found differences between publications of a study, we used data from the main paper(s) if no further information was found to support the use of one source of data versus another.
Where there were discrepancies in the data extracted by different review authors, we checked these against the original reports and resolved differences by discussion and consensus, with the involvement of a third author or a methodologist where appropriate. We contacted the original study authors for clarification or for missing data whenever possible.

For each study we documented the following information:

- Methods: study design (cross-over, parallel etc.), randomisation method, unit of randomisation, blinding method, duration of follow-up.

- Participants: setting, number of participants entered and analysed, age and sex, inclusion and exclusion criteria, levels of hearing impairment.

- Type of intervention: type of hearing aids fitted during the study, duration of each intervention, use of additional intervention, details of model, type of mould used and fitting strategy. We recorded the rehabilitation strategy used (such as the ability to position the aid and mould in the ear and to use the controls).

- Outcomes: assessment method, time point of data collection.

- Funding sources and declarations of interest.

In addition, we also extracted baseline information on prognostic factors (often called 'predictors' in trials) or effect modifiers that may affect preferences and the outcomes of the study. For this review, this included:

- levels or severity of hearing impairment;

- presence of asymmetric hearing loss;

- whether participants had previous experience of hearing aid use;

- cognitive impairment;

- visual impairment;

- presence of tinnitus.

For the outcomes of interest to the review, we extracted the findings of the studies on an available case analysis basis; i.e. we included data from all patients available at the time points based on the treatment randomised whenever possible, irrespective of compliance or whether patients had received the treatment as planned.

In addition to extracting pre-specified information about study characteristics and aspects of methodology relevant to risk of bias, we extracted the following summary statistics for each study and each outcome:

- For continuous data: the mean values, standard deviations and number of patients for each treatment group. We prioritised using change from baseline data whenever available. Where change data were not available, we used the mean and standard deviation of each group at the end of the study. We analysed data from measurement scales as continuous data.

- For binary data: the numbers of participants experiencing an event and the number of patients assessed at the time point.

- For ordinal scale data: if the data appeared to be approximately normally distributed or if the analysis that the investigators performed suggested parametric tests were appropriate, then we planned to treat the outcome measures as continuous data. 
Alternatively, if data were available, we planned to convert into binary data.

Where studies reported data at multiple time points, we only extracted the longest available data or end of the study data.

\section{Assessment of risk of bias in included studies}

SF and LYC undertook assessment of the risk of bias of the included studies independently, with the following taken into consideration, as guided by theCochrane Handbook for Systematic Reviews of Interventions (Handbook 2011):

- sequence generation;

- allocation concealment;

- blinding;

- incomplete outcome data;

- selective outcome reporting.

We used the Cochrane 'Risk of bias' tool in RevMan 5.3 (RevMan 2014), which involves describing each of these domains as reported in the study and then assigning a judgement about the adequacy of each entry: 'low', 'high' or 'unclear' risk of bias. For 'other sources of bias', we only considered the issue of validity and sensitivity of questionnaires as a high risk of bias if there was evidence or a strong rationale to believe that the lack of sensitivity would bias the results towards 'no difference', or the type of measure was unfairly favourable/unfavourable to either of the treatments. We planned to revisit and discuss disagreements with all authors until consensus was reached.

\section{Measures of treatment effect}

We planned to summarise dichotomous data as risk ratios (RR) with $95 \%$ confidence intervals $(95 \% \mathrm{Cl})$. For the key outcomes that we presented in the 'Summary of findings' table, we also expressed the results as absolute numbers based on the pooled results and compared to the assumed risk. We also planned to calculate the number needed to treat to benefit (NNTB) using the pooled results. The assumed baseline risk is typically either (a) the median of the risks of the control groups in the included studies, this being used to represent a 'medium-risk population' or, alternatively, (b) the average risk of the control groups in the included studies is used as the 'study population' (Handbook 2011). If a large number of studies had been available, and where appropriate, we may also have presented additional data based on the assumed baseline risk in (c) a low-risk population and (d) a high-risk population.

For continuous outcomes, we planned to summarise the treatment effect as the mean difference (MD) with $95 \% \mathrm{Cl}$ or as the standardised mean difference (SMD) with $95 \% \mathrm{Cl}$ if different scales had been used to measure the same outcome. We planned to provide a clinical interpretation of the SMD values.

We planned to dichotomise or analyse ordinal data as a continuous outcome, depending on the outcome and whether the scale could be expected to be normally distributed.

\section{Unit of analysis issues}

\section{Cross-over studies}

In addition to simple parallel randomised controlled trials (where the unit of randomisation is at the individual level), another possible design is a cross-over trial where patients are randomised to different fitting arrangements during different phases of the trial. When cross-over studies were found and included, our analyses were intended take into account the 'paired' nature of the data across different phases whenever possible (Elbourne 2002). If these data were not available, we analysed only the first phase of the study. By analysing only the first phase, carry-over effects are avoided.

Both of the above options were unavailable, except for some qualitatively reported data for two outcomes. There was only one outcome where data were consistently reported across all studies and we used the data at the end of the study as planned, and noted the risk of bias with this approach. Since this is a stable condition, we did not expect a patient's condition to fluctuate and hearing aids will only have an effect while they are in use. Any 'cross-over effect' is likely to be due to adaptation and experience of using of hearing aids. Using the end of study data is also reflective of clinical practice protocols where patients may be started with one or two hearing aids fitted and then try a different combination.

\section{Cluster-randomised studies}

For cluster-randomised trials, where patients may be randomised to either unilateral or bilateral fitting depending on the location or unit of practice, the unit of randomisation would be the unit or practice rather than the individual. For these designs, we planned to use the approximate analyses detailed in Chapter 16 of the Cochrane Handbook for Systematic Reviews of Interventions to either inflate the standard error or calculate the effective sample sizes (Handbook 2011). However, we found no cluster-randomised trials.

\section{Dealing with missing data}

If standard deviation data were not available, we planned to approximate these using the standard estimation methods from $\mathrm{P}$ values, standard errors or $95 \% \mathrm{Cls}$, if these were reported, as detailed in theCochrane Handbook for Systematic Reviews of Interventions (Handbook 2011). If it was impossible to estimate these, we planned to contact the study authors.

Apart from imputations for missing standard deviations, we planned to conduct no other imputations. We extracted and analysed all data using the available case analysis method whenever there were missing data.

\section{Assessment of heterogeneity}

We assessed clinical heterogeneity (which may be present even in the absence of statistical heterogeneity) by examining the included studies for potential differences between them in the types of participants recruited, interventions or controls used and outcomes measured. Noting the differences in designs and potential directions of the biases we decided that it would not be appropriate to pool the data on preference.

We had planned to assess statistical heterogeneity by visually inspecting the forest plots and considering the $\mathrm{Chi}^{2}$ test (with the threshold for significant heterogeneity being an associated $P$ value below 0.1 ). We also planned to express heterogeneity in terms of the $1^{2}$ statistic, which calculates the percentage of variability that is due to heterogeneity rather than chance with low, medium and high ranges of $20 \%$ to $40 \%, 41 \%$ to $60 \%$ and $61 \%$ to $100 \%$, respectively (Handbook 2011). 


\section{Assessment of reporting biases}

We assessed reporting bias as between-study publication bias and within-study outcome reporting bias.

\section{Outcome reporting bias (within-study reporting bias)}

We planned to assess within-study reporting bias by comparing the outcomes reported in the published report against the study protocol, whenever this could be obtained. If the protocol was not available, we compared the outcomes reported to those listed in the methods section. If results were mentioned but not reported adequately in a way that allows analysis (e.g. the report only mentions whether the results were statistically significant or not), bias in a meta-analysis is likely to occur. We sought further information from the study authors. If no further information could be found, we planned to note this as being a 'high' risk of bias. Quite often there was insufficient information to judge the risk of bias; we noted this as an 'unclear' risk of bias (Handbook 2011).

\section{Publication bias (between-study reporting bias)}

We planned to assess funnel plots if sufficient studies (more than 10) were available for an outcome. If we had observed asymmetry of the funnel plot, we would have conducted more formal investigation using the methods proposed by Egger 1997.

\section{Data synthesis}

We planned to conduct all meta-analyses using Review Manager 5.3 (RevMan 2014). For dichotomous data, we planned to analyse treatment differences as a risk ratio (RR) calculated using the Mantel-Haenszel method. We would have analysed time-to-event data using the generic inverse variance method.

For continuous outcomes, if all the data were from the same scale, we may have pooled mean values obtained at follow-up with change outcomes and report this as a MD. However, if the SMD had to be used as an effect measure, we would not have pooled change and endpoint data.

When statistical heterogeneity is low, random-effects versus fixedeffect methods yield trivial differences in treatment effects. However, when statistical heterogeneity is high, the random-effects method provides a more conservative estimate of the difference.

\section{Subgroup analysis and investigation of heterogeneity}

A number of factors could affect the relative benefit of binaural versus monaural hearing aids. If heterogeneity was detected, we planned to assess this using the following subgroup analyses, including:

- type of hearing aid;

- age;

- sex;

- severity of hearing loss - degree of hearing loss would be based on the better ear hearing threshold average as classified earlier;

- asymmetry of loss;

- cognitive impairment;

- visual impairment;

- presence of tinnitus with hearing loss;

- previous experience of using a hearing aid(s).
We intended to conduct some subgroup analyses for the type of hearing aid used regardless of whether statistical heterogeneity was observed, as this is widely suspected to be a potential effect modifier. We planned to present the main analyses of this review according to type of hearing aid. We planned to present all other subgroup analysis results in tables.

When studies had a mixed group of patients, we planned to analyse the study as one of the subgroups (rather than as a mixed group) if more than $80 \%$ of patients belonged to one category.

\section{Sensitivity analysis}

We planned to carry out sensitivity analyses to determine whether the findings were robust to the decisions made in the course of identifying, screening and analysing the studies. We planned to conduct sensitivity analysis for the following factors, whenever possible:

- impact of model chosen: fixed-effect versus random-effects model;

- risk of bias of included studies: excluding studies with high risk of bias (we defined these as studies that had a high risk of allocation concealment bias and a high risk of attrition bias (overall loss to follow-up of $>20 \%$, differential follow-up observed);

- how outcomes were measured: we planned to investigate the impact of including data where the validity of the measurement is unclear.

If any of these investigations found a difference in the size of the effect or heterogeneity, we planned to mention this in the 'Effects of interventions' section.

\section{GRADE and 'Summary of findings' table}

Two authors (LYC and SF) independently used the GRADE approach to rate the overall quality of evidence using GRADEpro GDT (https:// gradepro.org/). The quality of evidence reflects the extent to which we are confident that an estimate of effect is correct and we applied this in the interpretation of results. There are four possible ratings: high, moderate, low and very low. A rating of high quality of evidence implies that we are confident in our estimate of effect and that further research is very unlikely to change our confidence in the estimate of effect. A rating of very low quality implies that any estimate of effect obtained is very uncertain.

The GRADE approach rates evidence from RCTs that do not have serious limitations as high quality. However, several factors can lead to the downgrading of the evidence to moderate, low or very low. The degree of downgrading is determined by the seriousness of these factors:

- study limitations (risk of bias);

- inconsistency;

- indirectness of evidence;

- imprecision; and

- publication bias.

For this review, we identified the duration of use of hearing aids before outcome assessment as being important, as it will take some time before patients can adjust and fully benefit from the devices fitted. Therefore, for any outcomes where the duration of 
use was less than eight weeks, we downgraded the evidence for indirectness. We also considered downgrading in cases where the hearing aid technology used in the study is no longer reflective of currently available hearing aids.

We have included a 'Summary of findings' table, constructed according to the recommendations described in Chapter 10 of the Cochrane Handbook for Systematic Reviews of Interventions (Handbook 2011). We included the following outcomes in the 'Summary of findings' table:

- patient preference for bilateral versus unilateral aids;

- hearing-specific health-related quality of life;

- adverse effects (pain or discomfort in the ear, initiation or exacerbation of middle or outer ear infection);

- usage of hearing aids (e.g. data logging, battery consumption) for the duration of the trial;

- health-related quality of life;

- listening ability;

- sound localisation;

- speech in noise detection.

\section{RES U LTS}

\section{Description of studies}

\section{Results of the search}

In searches up to June 2017 we identified 2026 papers, reviews, conference abstracts and registered trials. We identified 41 additional references through other sources, including one included study identified from citations. After de-duplication 1092 records remained. We discarded all but 14 records. We formally excluded nine studies: five because they did not make a comparison between monaural and binaural fitting (Formby 2015; Kreisman 2010; Lavie 2014; Metselaar 2009; Yueh 2001), and four because they were not randomised (Boymans 2011; Gelfand 1987; McArdle 2012; Silman 1984). We included four randomised, cross-over studies in the review (Cox 2011; Erdman 1981; Stephens 1991; Vaughan-Jones 1993). There was an additional reference that reported follow-up data for Stephens 1991. We identified no ongoing studies and there are no studies awaiting assessment.

A PRISMA flow chart depicting the search process is shown in Figure 1. 
Figure 1. Process for sifting search results and selecting studies for inclusion

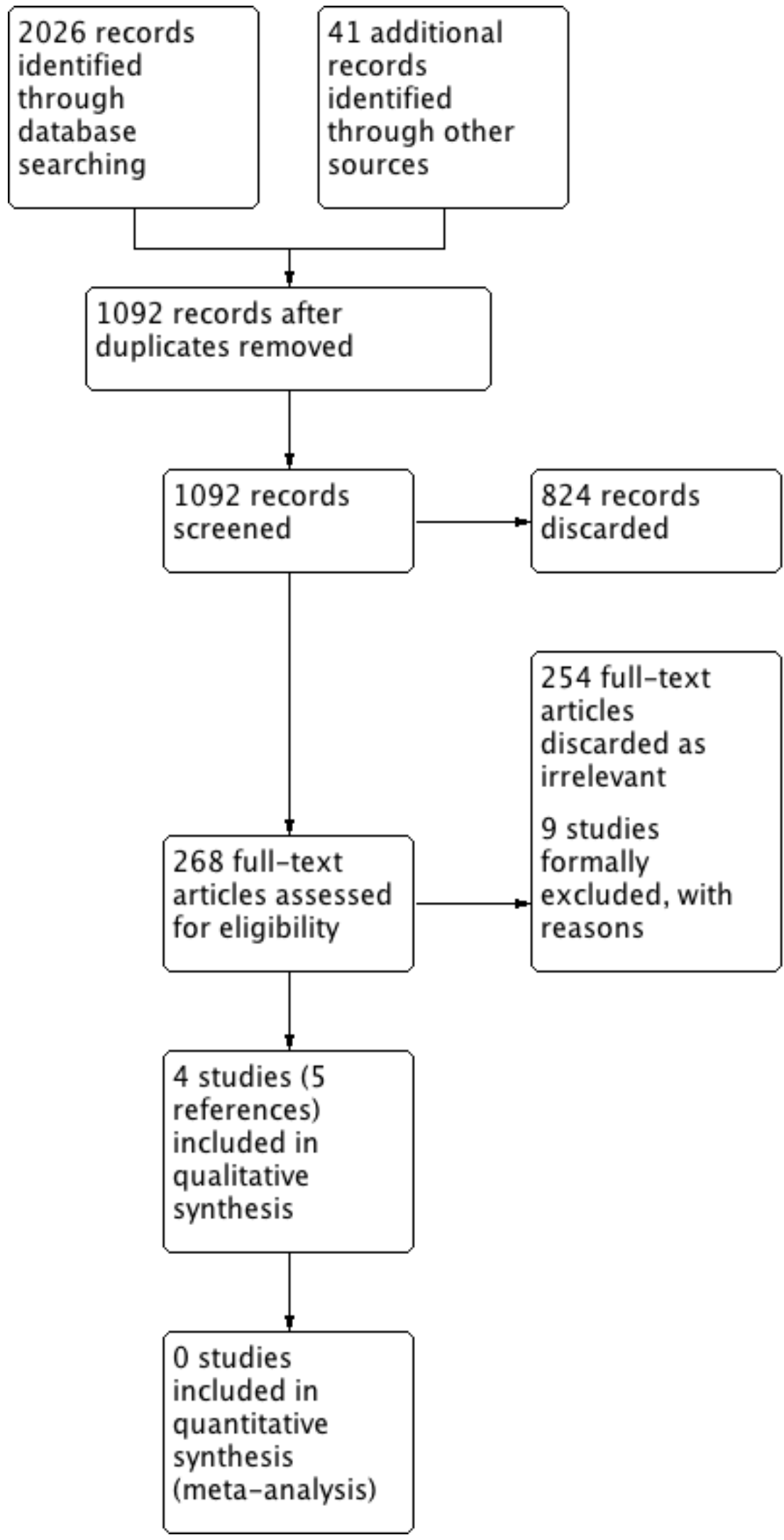




\section{Included studies}

We included four studies (Cox 2011; Erdman 1981; Stephens 1991; Vaughan-Jones 1993). See Characteristics of included studies.

\section{Design}

All studies used a randomised, cross-over design and compared monaural/binaural usage of hearing aids. Erdman 1981 used quasirandomisation (alternation).

Study duration varied between three and six months (three months in Erdman 1981; six months in Stephens 1991; 24 weeks in VaughanJones 1993). The Cox 2011 study was 12 weeks duration in total: a three-week period where participants were randomised to different orders of bilateral, left or right side fitting of hearing aids, followed by nine weeks where they used the hearing aids as desired (participants were "encouraged to experiment with using the hearing aids in different configurations").

Two studies had three arms (monaural right, monaural left, binaural) with different durations of use (10 weeks in VaughanJones 1993 and one week in Cox 2011). The other two studies had two arms (monaural, binaural) with different durations of use (two, four and seven days in Erdman 1981 and four to six weeks in Stephens 1991).

\section{Sample sizes}

Study sample sizes ranged between 30 (Erdman 1981) and 100 (Cox 2011). Only one study performed a power analysis to indicate the number of participants required (Cox 2011).

\section{Setting}

Two studies took place in US veterans audiology centres (Cox 2011; Erdman 1981). In addition to recruiting patients from the veterans centre, about half of the participants from Cox 2011 were recruited through an advertisement for adults interested in "new hearing aids".

The other two studies were carried out in UK National Health Service (NHS) audiology clinics with academic links (Stephens 1991; Vaughan-Jones 1993). Stephens 1991 recruited "healthy participants" through a survey of 604 adults attending two general practices. Two hundred and eighty-nine participants (out of 588 respondents) indicating a disability on a hearing questionnaire were invited for audiological assessment. Fortynine were eligible but 11 refused participation. Vaughan-Jones 1993 recruited patients who had been referred by their general practitioners to university hospital for provision of hearing aids.

\section{Participants}

The source of the participants varied greatly. In all studies the hearing in both ears had to be suitable for the provision of behindthe-ear hearing aids. However, no details were provided about the degree of asymmetry of hearing loss.

In Erdman 1981, the population were military personnel who had suffered from military noise-induced hearing loss. They had a mean age of 39.8 (range 23 to 58). Gender was not recorded but most, if not all, patients were likely to be men, given the setting and population at the time the study was conducted. Participants were issued with hearing aids free of charge in this study. The study did not provide specific inclusion criteria for the degree of hearing loss but reported that all of the participants had sensorineural hearing loss: 23 participants $(77 \%)$ had a high-frequency sensorineural hearing loss and seven participants $(23 \%)$ had a flat sensorineural hearing loss with a pure-tone average ranging from less than $30 \mathrm{~dB}$ to more than $51 \mathrm{~dB}$. Pure-tone audiometry was used to identify hearing level (only $0.5 \mathrm{kHz}, 1 \mathrm{kHz}, 1.5 \mathrm{kHz}$ and $2 \mathrm{kHz}$ were mentioned). The study reported that eight $(27 \%)$ of the patients had "asymmetrical hearing loss" but "both ears were aidable"; however, they did not provide details of the degree of asymmetry.

Stephens 1991 recruited patients with bilateral hearing impairment and without previous experience of hearing aid use. Participants were aged 50 to 65 (mean not reported); 23 were male and six female. Pure-tone averages were $\geq 30 \mathrm{~dB} \mathrm{HL}$ in both ears over $0.5 \mathrm{kHz}, 1 \mathrm{kHz}, 2 \mathrm{kHz}$ and $4 \mathrm{kHz}$. The study included those with asymmetric hearing loss (an image in the paper showed the difference in means between better and worse ears) but the degree of asymmetry allowed was not described, nor the type of hearing loss. The mean differences between ears in the study cohorts ranged between $3 \mathrm{~dB}$ and $7 \mathrm{~dB}$.

In Cox 2011, volunteer participants were recruited from two sources: a US veterans centre and advertisements. The veterans centre recruited male participants seeking amplification. Of the 98 male veterans considered, 49 met the inclusion criteria. The Hearing Aid Research Laboratory advertised for men and women interested in new hearing aids. Of 71 interested participants, 51 met the inclusion criteria. All participants were paid for their participation. Ages ranged from 50 to 85 (mean (SD) 70.1 (7.1)); 57 were male and 37 female. Eligibility in Cox 2011 was limited to those with symmetrical, sensorineural hearing loss. Pure-tone averages were 30 to $80 \mathrm{~dB} \mathrm{HL}$ in both ears over $0.5 \mathrm{kHz}, 1 \mathrm{kHz}$ and $2 \mathrm{kHz}$. Of the total 100 patients, six (6\%) withdrew and the remaining 94 patients all completed the study. Seventy-six (82\%) were new hearing aid users. Eighteen (19\%) owned and used one or two aids but did not know their preference for one or two aids. Thirty-two (68\%) of the veteran participants were provided with purchased aids that they could keep. All other patients $(n=62)$ were loaned their aids for the duration of the study.

In the Vaughan-Jones 1993 study, 64 consecutive patients were referred by their general practitioners for the provision of an NHS hearing aid. Participants were aged 40 to 83 (mean 67.9); 31 were male and 25 female. Mean pure-tone thresholds were $>25 \mathrm{~dB} \mathrm{HL}$ in both ears over $0.25 \mathrm{kHz}, 0.5 \mathrm{kHz}, 1 \mathrm{kHz}, 2 \mathrm{kHz}, 4 \mathrm{kHz}$ and $8 \mathrm{kHz}$. In this study, patients were given the chance to choose either bilateral or unilateral hearing aids at the first visit (before randomisation), but none of the patients chose binaural hearing aids. No data were given on the type or severity of the hearing impairments nor the number of patients with asymmetric hearing.

Patients with tinnitus associated with bilateral hearing loss were not specifically excluded in any of the studies. Only Vaughan-Jones 1993 specified an exclusion if this was the dominant reason for amplification; $45 \%$ of participants had tinnitus. The other studies did not report the percentage of patients with tinnitus.

Ethnicity was not reported in any study.

\section{Interventions}

All studies used the most relevant aids/moulds available at the time they were conducted - these are most likely analogue 
and not digital hearing aids. Only one study used acoustically programmable aids (Cox 2011).

The hearing aids used in Cox 2011 had to meet the following criteria to be consistent with the subject audiograms and with current practice in hearing aid fitting: (1) appropriate for a 30 to $80 \mathrm{~dB}$ $\mathrm{HL}$ three-frequency average sensorineural hearing loss with a flat or sloping configuration, (2) good-quality digital programmable device, (3) some form of compression, (4) a directional microphone (either fixed or adaptive technology) and (5) at least two programs (program 1 set for omni-directional and program 2 set for directional).

Following the fitting and orientation to the hearing aids, each participant was given a three-week wearing schedule to ensure that both unilateral and bilateral amplification were experienced in a variety of daily life settings. The wearing schedule encompassed three one-week periods during which each aid was worn unilaterally for one week and both were worn bilaterally for one week. There were six possible orders of the three conditions (left, right and both). Each block of six consecutive participants was randomised to the six orders so that all orders were used equally often.

Stephens 1991 used UK National Health Service BE 18 post-aural hearing aids with appropriate ear moulds (vented or open as individually indicated). Intervention Group 1 received binaural hearing aids (four to six weeks) and Intervention Group 2 received monaural hearing aids fitted to the preferred ear (four to six weeks). At the return visit the participants crossed over to the other arm.

In Vaughan-Jones 1993, a standard range of NHS aids were used to match the hearing impairment in 59 of the 61 patients and commercial aids were used in two patients. During the study 13 aids were made more powerful and one aid made less powerful. Uncomfortable listening level and uncomfortable loudness levels were used to guide choice of hearing aid. The study report does not comment on the choice of ear moulds.

The study was organised into five visits. At visit 1 bilateral impressions were taken. Four weeks later, at visit 2, participants were randomised to one of two groups: monaural aids left $(n=18)$ or right $(n=19)$; the remainder had binaural aids $(n=19)$. At visit 3, 10 weeks later, the monaural aid users changed their aid to the other ear; those with binaural aids had one aid randomly removed. Ten weeks later at visit 4 previous monaural aid users were given binaural aids; those who had initially had binaural aids change the side of use of the monaural aid. At visit 5, 10 weeks later, patient preference for aid use was recorded: binaural or monaural and, if the latter, which ear.

Erdman 1981 provided limited information on type/s of hearing aids used ("typically high pass instruments most frequently recommended"). No information was provided on the hearing aid fitting procedure.

In phase 1 , participants $(n=30)$ were fitted alternately with either monaural or binaural hearing aids in a counterbalanced fashion for a period of one hour each. In phase 2, participants were instructed to wear both binaural and monaural fittings for two consecutive days each. In phase 3 , participants were then permitted to utilise the preferred fitting primarily for an additional three days but they were instructed to continue to compare the other fitting in a variety of listening conditions.

\section{Outcomes}

\section{Primary outcomes}

\section{Patient preference for bilateral versus unilateral aids}

Cox 2011 reported patient preference and the reasons for the preference at the end of the 12-week study. By that time, the patients had already tried one week each for each possible configuration (left ear, right ear, both ears) in a random sequence (altogether three weeks), plus another nine weeks where the "subjects were given both hearing aids and instructed to continue to experiment with using the aids in different configurations...."). Participants were asked verbally in an exit interview about their preferences in 10 different situations, with a final question on the overall preference for unilateral or bilateral hearing aids. The investigators had prepared a questionnaire with 24 prespecified possible reasons for why people would prefer one versus two hearing aids and people were asked to choose the reasons that applied to them.

In Vaughan-Jones 1993, participants were given the chance to try each fitting for 10 weeks in a random sequence. At the end of the 30-week study, they were asked whether they preferred using one or two hearing aids, and why. Twice as many patients were fitted with monaural aids in phase 1 and the last phase of the study (37 monaural versus 19 binaural) before the preference questions were asked; there is therefore a risk of bias towards preference for the last fitting.

In Erdman 1981, participants were fitted with and wore each configuration for one hour in the first phase, before being asked to use the different fittings for two days each in the second phase. In the third phase, they were asked to use the preferred fitting for three days but continually compared it with the alternative. Subsequently, they were then followed up three months later. Preferences were asked at each phase and at the end of the three-month period. The study did not specify how they asked participants about the reasons for their preferences but presented two tables of "binaural advantages" and "binaural disadvantages" reported by patients.

In Stephens 1991, participants were fitted in a random order with a unilateral aid in the preferred ear and bilateral aids for four to six weeks in each fitting, before being asked if they wanted to continue having one aid or both aids at the end of the eight- to 12-week period. They also reported "reasons for dissatisfaction" with the monaural and binaural aids but, as in Erdman 1981, it was not specified how these were elicited.

\section{Secondary outcomes}

Usage of hearing aids (e.g. data logging, battery consumption) for the duration of the trial

Vaughan-Jones 1993 asked in a questionnaire "On average how many hours a day did you use the hearing aids?" Patients were given the choices: zero, less than 1,1 to 4,4 to 8,8 to 12 and 12 hours.

\section{Health-related quality of life}

None of the studies reported this. 
Listening ability

Cox 2011 measured the Abbreviated Profile of Hearing Aid Benefit (APHAB) at baseline and at the end of the overall study (not at the end of each phase) and analysed according to the preference of patients, rather than the randomised phases. Therefore, no data were available for the APHAB while patients were on unilateral or bilateral fitting.

\section{Audiometric benefit measured as binaural loudness summation}

None of the studies measured this.

\section{Outcome reported by carer or 'communication partner'}

None of the studies measured this.

\section{Annoyance, measured using patient-reported outcome measures}

None of the studies reported this.

\section{Sound localisation as measured by laboratory tests}

None of the studies reported this. However, Vaughan-Jones 1993 asked this question "When you hear a sound, e.g. a car horn, has this aid a) helped you to tell which direction the sound is coming from, b) made no difference, c) made it more difficult to tell which direction the sound is coming".

Figure 2. 'Risk of bias' graph: review authors' judgements about each risk of bias item presented as percentages across all included studies.

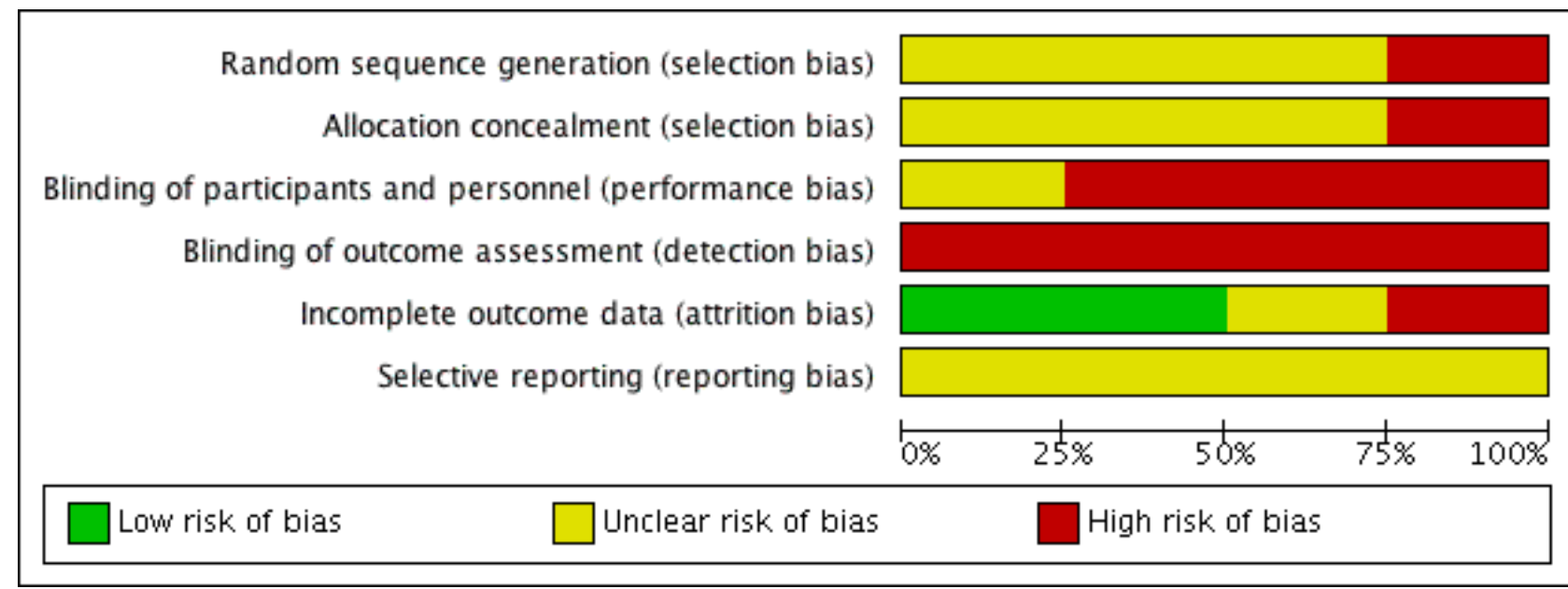


Figure 3. 'Risk of bias' summary: review authors' judgements about each risk of bias item for each included study.

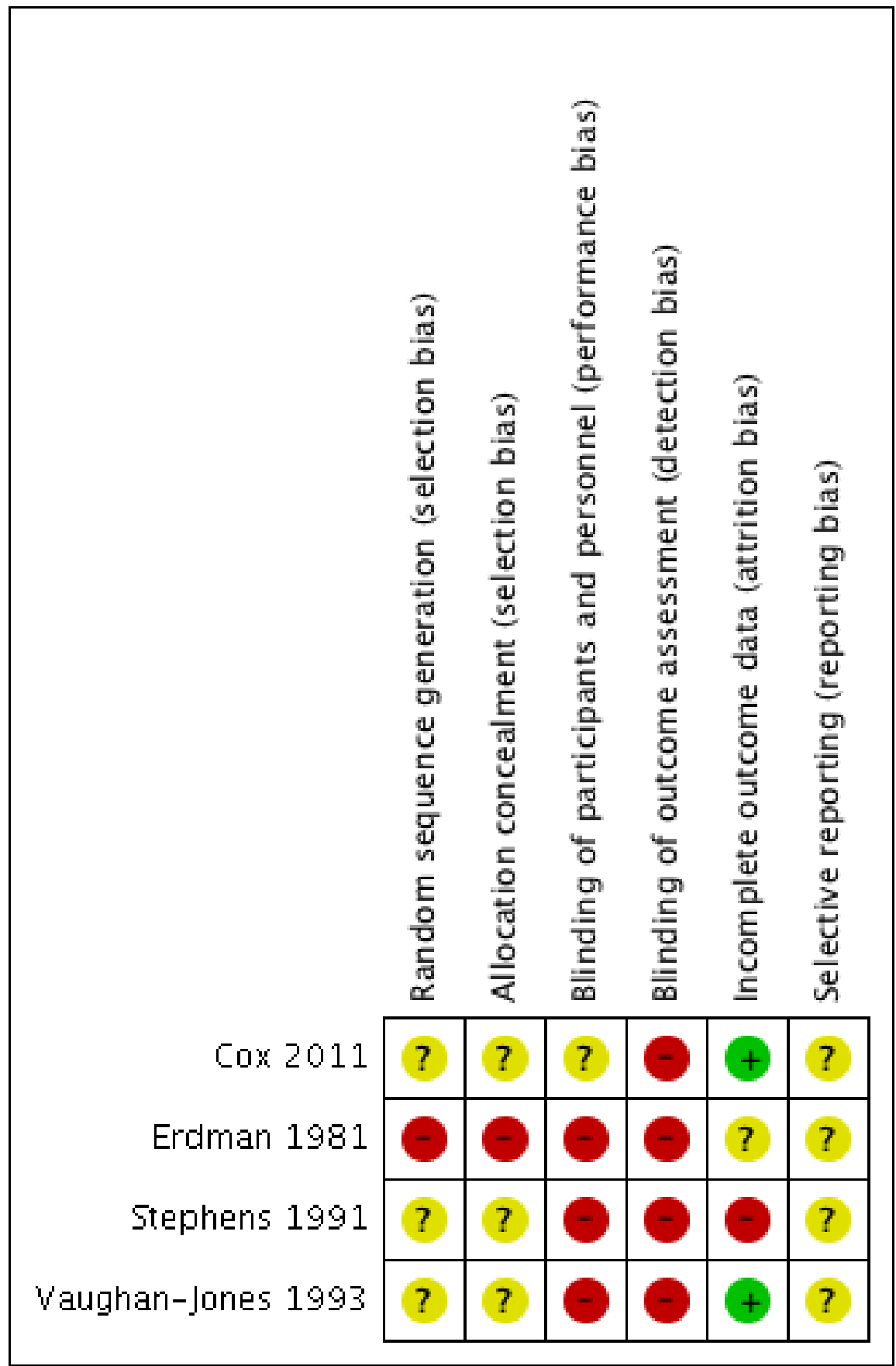

\section{Allocation}

\section{Random sequence generation}

Erdman 1981 has a high risk of bias for sequence generation because it used quasi-randomisation (fitting "alternatively ... in a counter balanced fashion").

Cox 2011 reported using blocked randomisation of six, for the six possible orders of the three conditions (left, right and both). However, as in Stephens 1991 and Vaughan-Jones 1993, the method of sequence generation was not reported. These studies have an overall unclear risk of bias for sequence generation.
Two of these studies randomised patients into three intervention arms: right, left and binaural (Cox 2011; Vaughan-Jones 1993). The Cox 2011 study used block of six randomisation to allocate patients into six possible sequences of usage, therefore twice as many patients were using the unilateral hearing aid configuration when the they were asked to use the hearing aids as preferred. On the other hand, Vaughan-Jones 1993 had nearly twice as many patients with binaural aids when the questions on preference were asked. The impact of randomisation sequence generation on preference is unknown; it is possible that patients may have a biased preference for the last used intervention when tested in a cross-over trial (this was detected in Vaughan-Jones 1993, analysed by the reviewers). 
These factors pose a risk of bias that could potentially favour the choice of hearing aids.

\section{Allocation concealment}

None of the studies reported their methods for allocation concealment. Apart from Erdman 1981, therefore, which used alternation and was at a high risk of bias, we considered the other studies at unclear risk of bias.

\section{Blinding}

There was a high risk of detection bias across all studies due to the lack of blinding. All the outcomes were patient-reported. In addition, the outcomes were mostly elicited by questionnaire or 'interview'. It was unclear whether the person collecting the data from the participant was a 'neutral' party or someone involved in the delivery of the intervention.

Apart from Cox 2011, which provided a clear protocol for fitting and follow-up, the other studies provided very little information about fitting or the information provided to patients and they are therefore at high risk of performance bias.

In addition, one of the studies reported that all patients expressed a preference for a unilateral hearing aid at the start of the study (Vaughan-Jones 1993). Therefore, there is a risk that the patients had a baseline preference for unilateral hearing aids, even before they tried any hearing aids. The risk of detection and performance bias could be further augmented in the absence of blinding.

\section{Incomplete outcome data}

The risk from loss to follow-up was low in two studies (6\% (6 out of 100 ) in Cox 2011 and 8\% (5 out of 61) in Vaughan-Jones 1993) to high in Stephens 1991 (24\% (9 out of 38)). Erdman 1981 did not report how many participants were randomised or whether there was any loss to follow-up (unclear risk).

\section{Selective reporting}

All studies reported the primary outcome of this review: patient preference for hearing aid.

Although three studies reported usage of hearing aids, data from two of these could not be used because they reported the mean daily usage according to the preferred fitting by the participants rather than usage while being allocated to bilateral versus unilateral hearing aids. These results do not tell us whether someone will use hearing aids more when they are allocated one or two hearing aids.
Most of the other outcomes were either not reported in a way that allowed for reporting by intervention (i.e. measured at the end of each phase, rather than at baseline or at the end of the overall study) or not fully reported. Without access to protocols, it is difficult to judge the risk of reporting bias.

\section{Other potential sources of bias}

There was a lack of use of validated measures to evaluate all the outcomes found and a lack of specific details on how data were collected. One of the studies reported that out of 56 participants, 38 (68\%) preferred a unilateral hearing aid at baseline, while the rest of the participants $(18,32 \%)$ had no preference (Vaughan-Jones 1993).

A combination of randomisation method (twice as many patients using unilateral fitting at any one time), baseline preference for unilateral hearing aids and the lack of blinding all point towards a high risk of bias for the outcome of preference.

\section{Effects of interventions}

See: Summary of findings for the main comparison Bilateral versus unilateral hearing aids for hearing loss in adults

\section{Bilateral versus unilateral hearing aids for hearing loss in adults}

There were insufficient data to conduct any of the planned subgroup analyses for all the outcomes. In all of the studies more than $80 \%$ of patients were first-time hearing aid users.

\section{Primary outcomes}

\section{Patient preference for bilateral versus unilateral aids}

All of the included studies reported patient preference at the end of the study. Vaughan-Jones 1993, however, did not report the reasons for the participants' preferences but reported the reasons for dissatisfaction instead.

Of these studies, two had allocated twice as many patients into the unilateral arms either through a 1:1:1 randomisation into left ear, right ear or bilateral (Cox 2011), or had randomised twice as many patients into the unilateral arm (Vaughan-Jones 1993). This means that patients spent twice as much time with a unilateral hearing aid and twice as many patients had a unilateral configuration as the last intervention.

Table 1: Percentages of patients who preferred bilateral hearing aids, time point of measurement and reasons reported for the stated preference

\begin{tabular}{|c|c|c|c|}
\hline Study & Time point of measure & $\begin{array}{l}\text { Percentage who } \\
\text { preferred bilateral }\end{array}$ & Reasons reported for preference \\
\hline \multirow[t]{2}{*}{ Cox 2011} & $\begin{array}{l}12 \text { weeks from the start of randomisation } \\
\text { (1-week trial of each configuration plus } 9 \\
\text { months "as desired") }\end{array}$ & $54 \%(51 / 94)$ & $\begin{array}{l}\text { Bilateral: balance, quality, comfort } \\
\text { ("more capable, secure, relaxed and } \\
\text { safe") }\end{array}$ \\
\hline & & & $\begin{array}{l}\text { Unilateral: comfort ("feeling more normal } \\
\text { and free, not closed in, plugged or cut } \\
\text { off"), quality, meets need (good enough) }\end{array}$ \\
\hline
\end{tabular}




$\begin{array}{lll}\begin{array}{l}\text { Vaughan-Jones } \\ 1993\end{array} & \begin{array}{l}\text { After } 6 \text { months, with } 10 \text { weeks in each } \\ \text { configuration }\end{array} & \text { 39\% (22/56) Not reported }\end{array}$

\begin{tabular}{ll}
\hline Stephens 1991 & $\begin{array}{l}\text { After } 8 \text { to } 12 \text { weeks, with } 4 \text { to } 6 \text { weeks in } \\
\text { each configuration }\end{array}$
\end{tabular}

$55 \%(16 / 29)$ reported for people who completed the study (in the paper published in 1991)
Bilateral: acoustic reasons; clarity, localisation, loudness

Unilateral: convenience, acoustic, psychological, others

\begin{tabular}{|c|c|c|c|}
\hline Erdman 1981 & $\begin{array}{l}\text { After } 3 \text { months of usage in the preferred } \\
\text { setting. First } 3 \text { phases consisted of } 1 \text { day } \\
\text { each and } 2 \text { days each for each configura- } \\
\text { tion, followed by another } 3 \text { days with the } \\
\text { preferred fitting. }\end{array}$ & $77 \%(23 / 30)$ & $\begin{array}{l}\text { Bilateral: "I can hear better", "I can hear } \\
\text { more easily" }\end{array}$ \\
\hline
\end{tabular}

\section{Hearing-specific health-related quality of life}

None of the studies reported health-related quality of life results at the end of each phase of the cross-over study.

\section{Adverse effects (pain or discomfort in the ear, initiation or exacerbation of middle or outer ear infection)}

None of the studies reported measuring adverse effects.

\section{Secondary outcomes}

Usage of hearing aids (e.g. data logging, battery consumption) for the duration of the trial

None of the studies used data logging or battery consumption. Vaughan-Jones 1993 used a questionnaire to find out for how many hours aids were used by participants. However, no details were available except that in the monaural hearing aid phase, $84 \%$ of respondents reported using "Often or all the time", whereas only $28 \%$ of respondents reported doing so while they were in the binaural phase.

\section{Generic health-related quality of life}

None of the studies reported using these measures.

\section{Listening ability}

None of the studies reported listening ability results at the end of each phase of the cross-over study.

\section{Audiometric benefit measured as binaural loudness summation}

None of the studies reported using these measures.

\section{Outcome reported by carer or 'communication partner' *}

None of the studies reported using these measures.

\section{Annoyance, measured using patient-reported outcome measures*}

None of the studies reported these measures.

\section{Sound localisation as measured by laboratory tests ${ }^{\star}$}

None of the studies reported laboratory tests.

Vaughan-Jones 1993 used a (non-validated) questionnaire and reported that "combined figures from all visits showed the surprising result that sound localisation was better when monoaurally aided" and "18\% found localisation worse when binaurally aided than when unaided" (42 respondents out of 56 ).

\section{Speech in noise detection as measured by laboratory tests*}

Vaughan-Jones 1993 used a (non-validated) questionnaire and stated that "Speech in noise was best in the monaurally aided, where $65 \%$ reported improvement and $43 \%$ of all patients felt binaural aid made speech in noise worse than when unaided". (Responses were obtained from 49 out of 56 respondents).

( ${ }^{\star}$ These additional outcomes were included as part of a collaboration with a NICE guideline committee and are not included in the 'Summary of findings' table of this review.)

\section{DISCUSSION}

\section{Summary of main results}

This review identified only four studies comparing the use of one hearing aid with two. The studies were small and included participants of widely varying ages. There was also considerable variation in the types and degree of sensorineural hearing loss that the participants were experiencing.

For the most part, the types of hearing aid evaluated would now be regarded, in high-income settings, as 'old technology', with only one study looking at 'modern' digital aids. However, the relevance of this is uncertain, as this review did not evaluate the differences in outcomes with the different types of technology.

We were unable to pool data from the four studies and the very low quality of the evidence leads us to conclude that we do not know if patients have a preference for one aid or two. Similarly, we do not know if hearing-specific health-related quality of life, or any of our other outcomes, is better with bilateral or unilateral aids.

\section{Overall completeness and applicability of evidence}

The evidence identified is relevant to the research question posed in this review, but is not sufficient to provide a clear answer to that question. The number of participants in the studies was small and, whilst a wide range of ages was represented, the age distribution does not necessarily reflect the global population of patients fitted with hearing aids for acquired hearing loss. 
Two factors may be relevant to any discussion about whether or not the evidence from studies conducted many years ago is relevant in the context of current practice. Firstly, there is uncertainty about whether or not findings relating to the hearing aids used over 20 years ago (when many hearing aids used analogue rather that digital technology) are applicable to current hearing aid use. This review did not evaluate the differences in outcomes with the different types of technology so this uncertainty is not resolved here. Secondly, as attitudes and beliefs can change over time, patient preferences (identified as our primary outcome) may or may not also change. This may impact on the applicability of results derived from studies conducted many years ago.

\section{Quality of the evidence}

The amount of evidence identified is small (four studies, 209 participants) and the quality for the only outcome for which data are available, that is patient preference for two hearing aids or one aid, is very low (GRADE). We downgraded the quality of evidence using the GRADE system for risk of bias, indirectness and imprecision.

There was serious risk of bias for all reported outcomes due to unclear or quasi-randomisation methods and lack of blinding. There was also serious risk of bias due to lack of blinding for patientreported subjective outcome measures and the lack of a specific protocol for fittings in most of the studies. Due to the small sample sizes of the studies, there is serious imprecision.

Regarding patients' preference for bilateral or unilateral aids, all studies asked this at the end of the cross-over trial, i.e. after having had a chance to try both fitting strategies. However, the use of three intervention arms (unilateral - left, unilateral - right and bilateral) meant that there was a 2:1 randomisation for unilateral versus bilateral hearing aids - so twice as many patients used the unilateral aids at any one time. This risks biasing the percentage of people preferring unilateral aids, if patients are more likely to choose the last-used fitting option. The validity and reliability of this method of measuring patients' preference has been questioned. Studies have suggested that a range of attributes are important to patients when deciding whether they prefer two hearing aids or one: for example, performance in quiet settings, comfort, feedback, frequency of battery replacement, purchase price, water and sweat resistance, and performance in noisy settings (Bridges 2012).

The absence of evidence for many outcomes, and the very low quality of the evidence relating to our primary outcome, means that there is no certainty about the relative merits of the alternative strategies.

\section{Potential biases in the review process}

The main methodological concern in this review is whether our searching and screening procedures have identified all relevant abstracts. This field has older literature that may not be well indexed in the major databases and the abstract and title are sometimes not a good reflection of the actual design and purpose of the study. To try to overcome these issues, we tested various search strategies (in collaboration with the National Institute for Health and Care Excellence (NICE)) and we also conducted additional searches that are not part of the usual process (for example, searching for forward citations of shortlisted/included studies (see Differences between protocol and review). Although we still cannot be completely confident that all possible studies were detected by the searches, we are confident that if such studies exist, they are unlikely to contribute high-quality evidence to this review. Moreover, the evidence described in this review has been presented to a committee of experts familiar with the field (the NICE clinical guideline panel for the adult-onset hearing loss guideline). If any relevant study was missing, we expect that the omission would have been identified.

Rather than being unduly conservative, we were more permissive in making decisions about the inclusion of studies in this review, given the scarcity of evidence in this area. We included a study where randomisation was done by alternation. In addition, we also included studies where the length of each phase was short (one day to two days in Erdman 1981, one week in Cox 2011) and the results at the end of each phase were not reported independently because we thought that the information on participant preference (collected at the end of another nine weeks in Cox 2011 and three months in Erdman 1981) would be useful. Although we had not planned to collect the reasons for participants' preferences, we extracted these data and reported them because we thought that this would be useful in providing some context for preference data.

\section{Agreements and disagreements with other studies or reviews}

A recent Cochrane Review concludes that hearing aids are effective at improving hearing-specific health-related quality of life, general health-related quality of life and listening abilities in adults with mild to moderate hearing loss (Ferguson 2017). The authors of that review felt that further studies were required to provide more information about the magnitude of the benefit, and how any benefit might vary according to the age and gender of the hearing aid user and the degree of their hearing loss. They also indicated that further research was needed to assess the relative merits of different types of hearing aid. We can now add to this the need for further research to determine if two aids are better than one.

\section{AUTHORS' CONCLUSIONS}

\section{Implications for practice}

The very low quality of the evidence leads us to conclude that we do not know if patients have a preference for one hearing aid or two. Similarly, we do not know if hearing-specific healthrelated quality of life, or any of our other outcomes, are better with bilateral or unilateral aids. The choice of fitting of hearing aids for patients with bilateral sensorineural hearing loss will be dependent on many factors, including the individual patient's circumstances, preferences and issues related to the healthcare setting.

\section{Implications for research}

High-quality research recommendations should ideally use the EPICOT framework and clearly specify the Populations (P), Interventions (I), Comparisons (C) and Outcomes of interest (O). Many of the comments made by Ferguson et al in their review on hearing aids for people with mild to moderate hearing loss (Ferguson 2017) are also relevant to the one versus two hearing aid question.

Those participating in trials should be representative of the populations around the world who are receiving hearing aids for the first time. Sample sizes need to be sufficient to answer the study 
question reliably. The type of hearing aids offered must be clearly specified and the fitting strategies well described. It is critical that appropriate outcomes are chosen and it would be ideal if the choice was consistent across studies. A 'core outcome set' for hearing aid research would be particularly helpful. The measurement of outcomes is also extremely important and at the present time may be problematic. Generally accepted generic health-related quality of life measures may not be adequately sensitive when evaluating the effects of interventions to improve hearing and listening. Only when the most useful primary outcomes and their measures have been identified can the minimal clinically important difference be determined to guide both trials and meta-analyses.

In clinical practice, most clinicians consider the preference of the individual patient to be most important in their decision to fit one or two hearing aids (Sereda 2015). However, it is unclear whether asking patients which options they prefer at the end of a randomised controlled trial is valid (internally and externally) and reliable. Specific study designs and methods to measure patient preference (e.g. Baskerville 1984; Bridges 2012) should be considered in future research.

Minimising the risk of performance and detection bias is especially difficult in hearing aid trials. Ferguson 2017 points out that assessment of patient-reported outcomes may be blinded by - for example - using telephone or web-based administration of questionnaires, depending on the communication abilities of participants.

\section{ACKNOWLEDGEMENTS}

This project was supported by the National Institute for Health Research, via Cochrane Infrastructure, Cochrane programme Grant or Cochrane Incentive funding to Cochrane ENT. The views and opinions expressed therein are those of the authors and do not necessarily reflect those of the Systematic Reviews Programme, NIHR, NHS or the Department of Health.

We would especially like to acknowledge Professor George Browning, Mr Patrick Howell, Dr William Whitmer and Dr Graham Naylor, who co-authored the protocol for this review, and their funder, the Scottish Section MRC/CEO Institute of Hearing Research, UK.

We thank Joanna Ashe, Senior Information Specialist at NICE, for her help in designing the search strategy.

Finally, we are indebted to Professor Stephen O'Leary for acting in the capacity of Co-ordinating Editor for this review. 


\section{RE F E R E N C E S}

\section{References to studies included in this review}

Cox 2011 \{published data only\}

Cox RM, Schwartz KS, Noe CM, Alexander GC. Preference for one or two hearing aids among adult patients. Ear and Hearing 2011;32(2):181-97. [DOI: 10.1097/AUD.0b013e3181f8bf6c]

\section{Erdman 1981 \{published data only\}}

Erdman SA, Sedge RK. Subjective comparisons of binaural versus monaural amplification. Ear and Hearing 1981;2(5):225-9.

\section{Stephens 1991 \{published data only\}}

Gianopoulos I, Stephens D. Opting for two hearing aids: a predictor of long-term use among adult patients fitted after screening. International Journal of Audiology 2002;41(8):518-26. [PUBMED: 12477172]

* Stephens SD, Callaghan DE, Hogan S, Meredith R, Rayment A, Davis A. Acceptability of binaural hearing aids: a cross-over study. Journal of the Royal Society of Medicine 1991;84(5):267-9.

Vaughan-Jones 1993 \{published data only\}

Vaughan-Jones RH, Padgham ND, Christmas HE, Irwin J, Doig MA. One aid or two?--more visits please!. Journal of Laryngology and Otology 1993;107(4):329-32.

\section{References to studies excluded from this review}

Boymans 2011 \{published data only\}

Boymans M, Dreschler WA. Unilateral versus bilateral hearing aid fittings. In: Strumillo P editor(s). Advances in Sound Localization. Available from: https://www.intechopen.com/ books/advances-in-sound-localization/unilateral-versusbilateral-hearing-aid-fittings. InTech, 2011:283-96. [DOI: 10.5772/15690]

\section{Formby 2015 \{published data only\}}

Formby C, Hawley ML, Sherlock LP, Gold S, Payne J, Brooks R, et al. A sound therapy-based intervention to expand the auditory dynamic range for loudness among persons with sensorineural hearing losses: a randomized placebo-controlled clinical trial. Seminars in Hearing 2015;36(2):77-110.

\section{Gelfand 1987 \{published data only\}}

Gelfand SA, Silman S, Ross L. Long-term effects of monaural, binaural and no amplification in subjects with bilateral hearing loss. Scandinavian Audiology 1987;16(4):201-7.

\section{Kreisman 2010 \{published data only\}}

Kreisman BM, Mazevski AG, Schum DJ, Sockalingam R. Improvements in speech understanding with wireless binaural broadband digital hearing instruments in adults with sensorineural hearing loss. Trends in Amplification 2010;14(1):3-11.

\section{Lavie 2014 \{published data only\}}

Lavie L, Banai K, Attias J, Karni A. Better together: reduced compliance after sequential versus simultaneous bilateral hearing aids fitting. American Journal of Audiology 2014;23(1):93-8.

McArdle 2012 \{published data only\}

McArdle RA, Killion M, Mennite MA, Chisolm TH. Are two ears not better than one?. Journal of the American Academy of Audiology 2012;23:171-81.

\section{Metselaar 2009 \{published data only\}}

Metselaar M, Maat B, Krijnen P, Verschuure H, Dreschler WA, Feenstra L. Self-reported disability and handicap after hearingaid fitting and benefit of hearing aids: comparison of fitting procedures, degree of hearing loss, experience with hearing aids and uni- and bilateral fittings. European Archives of OtoRhino-Laryngology 2009;266(6):907-17.

\section{Silman 1984 \{published data only\}}

Silman S, Gelfand SA, Silverman CA. Late-onset auditory deprivation: effects of monaural versus binaural hearing aids. Journal of the Acoustical Society of America 1984;76(5):1357-62.

\section{Yueh 2001 \{published data only\}}

Yueh B, Souza PE, McDowell JA, Collins MP, Loovis CF, Hedrick SC, et al. Randomized trial of amplification strategies. Archives of Otolaryngology -- Head \& Neck Surgery 2001;127(10):1197-204.

\section{Additional references}

\section{Baskerville 1984}

Baskerville JC, Toogood JH, Mazza J, Jennings B. Clinical trials designed to evaluate therapeutic preferences. Statistics in Medicine 1984;3(1):45-55.

\section{Bridges 2012}

Bridges JF, Lataille AT, Buttorff C, White S, Niparko JK. Consumer preferences for hearing aid attributes: a comparison of rating and conjoint analysis methods. Trends in Amplification 2012;16(1):40-8. [DOI: 10.1177/1084713811434617]

\section{Dillon 2012}

Dillon H (editor). Hearing Aids. 2nd Edition. Sydney/New York: Boomerang Press/Thieme, 2012.

\section{Egger 1997}

Egger M, Davey Smith G, Schneider M, Minder C. Bias in meta-analysis detected by a simple, graphical test. BMJ 1997;315(7109):629-34.

\section{Elbourne 2002}

Elbourne DR, Altman DG, Higgins JP, Curtin F, Worthington HV, Vail A. Meta-analyses involving cross-over trials: methodological issues. International Journal of Epidemiology 2002;31(1):140-9.

\section{Ferguson 2017}

Ferguson MA, Kitterick PT, Chong LY, Edmondson-Jones M, Barker F, Hoare DJ. Hearing aids for mild to moderate hearing 
loss in adults. Cochrane Database of Systematic Reviews 2017, Issue 9. [DOI: 10.1002/14651858.CD012023.pub2]

\section{Handbook 2011}

Higgins JPT, Green S (editors). Cochrane Handbook for Systematic Reviews of Interventions Version 5.1.0 [updated March 2011]. The Cochrane Collaboration, 2011. Available from www.cochrane-handbook.org.

\section{Laplante-Levesque 2014}

Laplante-Levesque A, Nielsen C, Jensen LD, Naylor G. Patterns of hearing aid usage predict hearing aid use amount (data logged and self-reported) and overreport. Journal of the American Academy of Audiology 2014;25:187-98.

\section{Livingston 2017}

Livingston G, Sommerlad A, Orgeta V, Costafreda SG, Huntley J, Ames $D$, et al. Dementia prevention, intervention, and care. Lancet 2017 Jul 19 [Epub ahead of print]. [DOI: 10.1016/ S0140-6736(17)31363-6]

\section{CHARACTERISTICS OF STUDIES}

Characteristics of included studies [ordered by study ID]

\section{RevMan 2014 [Computer program]}

The Nordic Cochrane Centre, The Cochrane Collaboration. Review Manager (RevMan). Version 5.3. Copenhagen: The Nordic Cochrane Centre, The Cochrane Collaboration, 2014.

\section{Sereda 2015}

Sereda M, Hoare DJ, Nicholson R, Smith S, Hall DA. Consensus on hearing aid candidature and fitting for mild hearing loss, with and without tinnitus: Delphi review. Ear and Hearing 2015;36(4):417-29. [DOI: 10.1097/AUD.0000000000000140]

\section{WHO 1991}

World Health Organization. Report of the Informal Working Group on prevention of deafness and hearing impairment programme planning. Geneva: WHO, 1991.

* Indicates the major publication for the study

\section{Cox 2011}

Methods Randomised, cross-over trial (1 week each of bilateral, left or right ear), followed by another 9 weeks where patients used the devices "as desired"

Total of 12 weeks follow-up, mean 94 days (range 74 to 161 days)

Participants

Location: 2 centres from the USA around 2005-2007, University of Memphis Hearing Aid Research Laboratory (HARL) and Mountain Home Veterans Affairs Medical Centre

Setting of recruitment and treatment: The Veterans Centre (recruited males seeking hearing aid amplification) and The University School (advertised for adults interested in "new" hearing aids)

\section{Sample size:}

- Number randomised: 100 (49 out of 98 veterans screened, 51 out of 71 interested respondents to an advertisement)

- Number completed: 94

Participant (baseline) characteristics:

- Age: between 50 and 85 years; mean (SD) 70.1 (7.1) years

- Gender: 57 male, 37 female

- Ethnicity: not stated

- Main diagnosis: bilateral symmetrical hearing loss

Other important effect modifiers:

- Hearing loss status: bilateral, symmetric, pure-tone average (over $0.5 \mathrm{kHz}, 1 \mathrm{kHz}$ and $2 \mathrm{kHz}$ ) of 30 to $80 \mathrm{~dB} \mathrm{HL}$

- Degree of asymmetry: only bilaterally symmetric patients recruited

- Previous experience of hearing aid use: 76 (82\%) were new hearing aid users; 18 (19\%) owned and used 1 or 2 aids but did not have a preference for 1 or 2 aids

- Cognitive impairment: adequate literacy and cognitive competence to respond to questionnaires; active lifestyle, good health

- Visual impairment: not stated 
Cox 2011 (Continued)

- Presence of tinnitus: percentage not stated

\section{Inclusion criteria:}

- Aged between 50 and 85 years

- Bilateral, symmetric, stable sensorineural impairments with a better pure-tone average (over $0.5 \mathrm{kHz}$, $1 \mathrm{kHz}$ and $2 \mathrm{kHz}$ ) of 30 to $80 \mathrm{~dB}$ hearing loss

- Open-mindedness to preference for using one or two aids

- Normal middle ear pressure (immittance) test results

- Active lifestyle, good health

- Adequate literacy and cognitive competence to respond to questionnaires

- Willingness to wear the aid/s at least 4 hours per day

\section{Exclusion criteria:}

- Existing preference for either 1 or 2 hearing aids

- Observed or reported neurologic or psychiatric disorders

- Fluctuating hearing

Chronic middle or external ear disease

Patients were randomised to wearing the hearing aids on the right, left or bilaterally in a random sequence for 1 week in each configuration (total of 3 weeks). Subsequently, patients used the hearing aids as desired ("encouraged to experiment with using the hearing aids in different configurations").

Considerable efforts were made to optimise the hearing aid flitting by recognised audiometric assessment techniques as detailed in the paper.

The hearing aids in this study met the following criteria consistent with current fitting practice:

- Appropriate for a 30 to $80 \mathrm{~dB}$ HL 3-frequency average sensorineural hearing loss with a flat or sloping configuration

- Good-quality digital programmable device

- Some form of compression

- A directional microphone (either fixed or adaptive technology)

- At least 2 programs (omni-directional and directional)

The style of hearing aid was chosen as appropriate and was distributed as follows:

- Behind-the-ear: 73

- In-the-ear: 18

- In-the-canal: 2

- Completely-in-the-canal: 1

\section{Outcomes Primary outcomes}

Patient preference for bilateral versus unilateral aids (NIDCD)

\section{Declarations of interest}

$$
\text { No information provided }
$$

Notes

$$
\begin{aligned}
& \text { All participants were paid for their participation; } 32 \text { of the } 94(34 \%) \text { were allowed to retain their aids } \\
& \text { free of charge at the end of the study. } \\
& \text { The study measured number of hours of usage and also used a number of other outcome measures } \\
& \text { (hearing-specific health-related quality of life - Auditory Lifestyle and Demand Questionnaire (ALDQ), }
\end{aligned}
$$


Cox 2011 (Continued)

International Outcome Inventory of Hearing Aids (IOI-HA), Binaural Test Battery, Device Orientated Subjective Outcome (DOSO) Scale, Abbreviated Profile of Hearing Aid Benefit (APHAB)), but these were either measured at baseline or at the end of the study and analysed according to patient preference for device, i.e. they were not analysed according to preference randomised phase.

\section{Risk of bias}

\begin{tabular}{|c|c|c|}
\hline Bias & Authors' judgement & Support for judgement \\
\hline $\begin{array}{l}\text { Random sequence genera- } \\
\text { tion (selection bias) }\end{array}$ & Unclear risk & $\begin{array}{l}\text { Block (of } 6 \text { ) randomisation was used but the method of sequence generation } \\
\text { was not reported. There were } 6 \text { possible orders of the } 3 \text { conditions (left, right } \\
\text { and both). Each block of } 6 \text { consecutive participants was randomised to the } 6 \\
\text { orders so that all orders were used equally often. }\end{array}$ \\
\hline $\begin{array}{l}\text { Allocation concealment } \\
\text { (selection bias) }\end{array}$ & Unclear risk & No information provided \\
\hline $\begin{array}{l}\text { Blinding of participants } \\
\text { and personnel (perfor- } \\
\text { mance bias) } \\
\text { All outcomes }\end{array}$ & Unclear risk & $\begin{array}{l}\text { No blinding was done; however, a clear protocol for fitting of hearing aids was } \\
\text { provided }\end{array}$ \\
\hline $\begin{array}{l}\text { Blinding of outcome as- } \\
\text { sessment (detection bias) } \\
\text { All outcomes }\end{array}$ & High risk & $\begin{array}{l}\text { No blinding of participants or outcome assessors } \\
\text { Comment: outcomes were subjective and patient-reported }\end{array}$ \\
\hline $\begin{array}{l}\text { Incomplete outcome data } \\
\text { (attrition bias) } \\
\text { All outcomes }\end{array}$ & Low risk & $\begin{array}{l}94 \% \text { (94 of } 100 \text { ) patients completed the study; } 6 \text { withdrew for "personal rea- } \\
\text { sons" } \\
\text { Comment: small percentage of loss to follow-up }\end{array}$ \\
\hline $\begin{array}{l}\text { Selective reporting (re- } \\
\text { porting bias) }\end{array}$ & Unclear risk & $\begin{array}{l}\text { The methods section indicated that additional outcomes were obtained dur- } \\
\text { ing the exit interview but these were not reported. We were unable to assess } \\
\text { the risk without access to the study protocol. }\end{array}$ \\
\hline
\end{tabular}

\section{Erdman 1981}

Methods Quasi-randomised (alternation), cross-over study; total study length 3 months

Participants

Location: USA; the Army Audiology and Speech Centre, Washington DC

Setting of recruitment and treatment: 30 military personnel attending a military aural rehabilitation programme

\section{Sample size:}

- Number randomised: 30

- Number completed: 30

\section{Participant (baseline) characteristics:}

- Age: range 23 to 58 years old with a mean of 39.8 years

- Gender: not stated

- Ethnicity: not stated

- Main diagnosis: bilateral hearing loss due to military (noise) induced hearing loss

Other important effect modifiers: 
- Hearing loss status: no criterion for average hearing loss given for eligibility

* $10(10 / 30,33 \%)$ of participants with pure-tone thresholds $<25 \mathrm{~dB} \mathrm{HL}$ and below

* $23(23 / 30,77 \%)$ of the soldier participants had high-frequency (>2 kHz) sensorineural hearing loss secondary to long-term noise exposure; high-frequency loss was not quantified

* $7(7 / 30,23 \%)$ participants had a flat sensorineural hearing loss; PTA in range $<30 \mathrm{~dB}$ HL to $>51 \mathrm{~dB} \mathrm{HL}$

- Degree of asymmetry: 8 (8/30, 27\%) had asymmetrical hearing (not defined) loss but both ears were aidable

- Whether participants had previous experience of hearing aid use: not stated

- Cognitive impairment: not stated

- Visual impairment: not stated

- Presence of tinnitus: not stated

Inclusion criteria: military personnel attending a comprehensive aural rehabilitation programme at the centre (inclusion criteria not explicitly stated)

Exclusion criteria: not stated

Interventions Intervention group $(\mathbf{n}=\mathbf{3 0})$ :

Intervention 1: unilateral hearing aid (unclear which ear was fitted and how that was chosen)

Intervention 2: bilateral hearing aids

Patients used both fittings in 3 phases and were then followed up for 3 months

- Phase 1: participants $(n=30)$ fitted alternately with either monaural or binaural hearing aids in a counter balanced fashion for a period of 1 hour each (assumption $n=15$ monaurally aided 1 st and $n$ $=15$ binaurally aided $1 \mathrm{st}$ )

- Phase 2: participants were next instructed to wear both binaural and monaural fittings for 2 consecutive days each

- Phase 3: participants were then permitted to utilise primarily the preferred fitting for an additional 3 days but were instructed to continue to compare the other fitting in a variety of listening conditions. Limited information on type/s of hearing aids used; typically high pass instruments most frequently recommended. No data on hearing aid fitting procedure.

Follow-up phase: participants fitted with amplification based on preference reported at the end of Phase 3

Outcomes Primary outcomes

Patient preference for bilateral versus unilateral aids at the end of each phase and at the end of the 3month follow-up

\begin{tabular}{ll}
\hline Funding sources & No information provided \\
\hline Declarations of interest & No information provided \\
\hline Notes & -
\end{tabular}

\section{Risk of bias}

\begin{tabular}{lll}
\hline Bias & Authors' judgement & Support for judgement \\
\hline $\begin{array}{l}\text { Random sequence genera- } \\
\text { tion (selection bias) }\end{array}$ & High risk & $\begin{array}{l}\text { Quote: "fitted alternatively with either monaural or binaural hearing aids in a } \\
\text { counter balanced fashion" ... (Phase I),... "instructed to wear ... consecutive- } \\
\text { ly" (Phase II), "permitted to use primarily the preferred fitting" (Phase III) }\end{array}$ \\
& $\begin{array}{l}\text { Comment: it is only clear that there was an attempt to quasi-randomise pa- } \\
\text { tients to binaural or monaural by alternation in Phase I, which lasted only }\end{array}$
\end{tabular}


1 hour. It was unclear if there were further attempts to alternate patients in Phase II.

\begin{tabular}{lll}
\hline $\begin{array}{l}\text { Allocation concealment } \\
\text { (selection bias) }\end{array}$ & High risk & $\begin{array}{l}\text { Since alternation was used, allocation concealment is unlikely to have been } \\
\text { possible }\end{array}$ \\
\hline $\begin{array}{l}\text { Blinding of participants } \\
\begin{array}{l}\text { and personnel (perfor- } \\
\text { mance bias) }\end{array}\end{array}$ & High risk & $\begin{array}{l}\text { There was no mention of blinding, the fitting protocol or the type of informa- } \\
\text { tion given to patients }\end{array}$ \\
All outcomes &
\end{tabular}

\begin{tabular}{|c|c|c|}
\hline $\begin{array}{l}\text { Blinding of outcome as- } \\
\text { sessment (detection bias) }\end{array}$ & High risk & $\begin{array}{l}\text { Patients were aware of the fitting; all outcomes were subjective and pa- } \\
\text { tient-reported }\end{array}$ \\
\hline
\end{tabular}

All outcomes

\begin{tabular}{|c|c|c|}
\hline $\begin{array}{l}\text { Incomplete outcome data } \\
\text { (attrition bias) } \\
\text { All outcomes }\end{array}$ & Unclear risk & $\begin{array}{l}\text { There was no description of loss to follow-up. It is likely that all participants } \\
\text { were followed up due to the duration, type of participants and centre of the } \\
\text { study. }\end{array}$ \\
\hline
\end{tabular}

Selective reporting (re- Unclear risk No access to protocol: insufficient information to judge
porting bias)

\section{Stephens 1991}

Methods Randomised, cross-over trial; total of 6 months follow-up

\section{Participants}

Location: UK (Wales); Welsh Institute of Hearing Research

Setting of recruitment and treatment: patients from 2 general practices responded to a hearing disability questionnaire indicating a disability (588 responded out of 604 asked) and were invited for audiological assessment (289 assessed); 49 were eligible but 11 (22\%) refused participation

\section{Sample size:}

- Number randomised: 38 out of 49 eligible patients (11 refused participation)

- Number completed: 29

\section{Participant (baseline) characteristics:}

- Age: 50 to 65 years

- Gender: 23 male, 6 female

- Ethnicity: not stated

- Main diagnosis: bilateral hearing impairment

Other important effect modifiers:

- Hearing loss status: bilateral hearing impairment equal to or worse than $30 \mathrm{~dB} \mathrm{HL}$ (average over 0.5 $\mathrm{kHz}, 1 \mathrm{kHz}, 2 \mathrm{kHz}$ and $4 \mathrm{kHz}$ ) in the better ear

- Degree of asymmetry: asymmetrical hearing loss patients included

- Whether participants had previous experience of hearing aid use: no patients had previously used a hearing aid

- Cognitive impairment: not stated

- Visual impairment: not stated

- Presence of tinnitus: percentage not stated 
Inclusion criteria: aged 50 to 65 years, a bilateral hearing impairment equal to or worse than $30 \mathrm{~dB}$ $\mathrm{HL}$ (average over $0.5 \mathrm{kHz}, 1 \mathrm{kHz}, 2 \mathrm{kHz}$ and $4 \mathrm{kHz}$ ) in the better ear and had not previously used hearing aids

Exclusion criteria: previous hearing aid use

Intervention groups (total $\mathbf{n}=\mathbf{2 9}$ completed):
Intervention 1: binaural hearing aids (4 to 6 weeks)
Intervention 2: monaural hearing aids to preferred ear (4 to 6 weeks)
Patients crossed over to the other arm after the 4- to 6-week period
Type of hearing aid fitted: UK National Health Service BE 18 post-aural hearing aids with appropriate
ear moulds, vented or open as individually indicated

\begin{tabular}{ll}
\hline Outcomes & Primary outcomes \\
& - Patient preference for bilateral versus unilateral aids \\
& Secondary outcomes \\
& - Speech in noise using FAAF at a signal ratio of $0 \mathrm{~dB}$ \\
& - Sound localisation \\
\hline Funding sources & Welsh Institute of Hearing Research and the MRC Institute of Hearing Research \\
\hline Declarations of interest & No information provided \\
\hline Notes & $\begin{array}{l}\text { Hearing-specific health-related quality of life - Social Hearing Handicap Index (SHHI) \& Emotional Re- } \\
\text { sponse to Hearing Loss (ERS) measured after preferences were reported }\end{array}$
\end{tabular}

\section{Risk of bias}

\begin{tabular}{|c|c|c|}
\hline Bias & Authors' judgement & Support for judgement \\
\hline $\begin{array}{l}\text { Random sequence genera- } \\
\text { tion (selection bias) }\end{array}$ & Unclear risk & $\begin{array}{l}\text { Method of randomisation not stated. Numbers of patients in each of the } 2 \\
\text { arms not stated. No data reported to demonstrate that the variables that } \\
\text { might affect the outcomes were evenly distributed. }\end{array}$ \\
\hline $\begin{array}{l}\text { Allocation concealment } \\
\text { (selection bias) }\end{array}$ & Unclear risk & No information provided \\
\hline $\begin{array}{l}\text { Blinding of participants } \\
\text { and personnel (perfor- } \\
\text { mance bias) } \\
\text { All outcomes }\end{array}$ & High risk & No information about blinding or fitting protocol provided \\
\hline $\begin{array}{l}\text { Blinding of outcome as- } \\
\text { sessment (detection bias) } \\
\text { All outcomes }\end{array}$ & High risk & All outcomes were patient-reported \\
\hline $\begin{array}{l}\text { Incomplete outcome data } \\
\text { (attrition bias) } \\
\text { All outcomes }\end{array}$ & High risk & $\begin{array}{l}76 \% \text { of patients ( } 29 \text { of } 38 \text { ) completed the study for the } 6 \text {-month follow-up } \\
\text { (preference data). The number of participants excluded was high. For the } 10- \\
\text { year follow-up the study reported that } 29 / 41 \text { were traced: } 12 / 22 \text { bilateral and } \\
17 / 19 \text { unilateral patients were still alive. }\end{array}$ \\
\hline $\begin{array}{l}\text { Selective reporting (re- } \\
\text { porting bias) }\end{array}$ & Unclear risk & $\begin{array}{l}\text { Some scales (e.g. SHHI and ERS) were measured but only results at the end } \\
\text { versus baseline (rather than between groups) were reported }\end{array}$ \\
\hline
\end{tabular}




\begin{tabular}{ll} 
Methods & Randomised, cross-over study \\
\hline Participants & Location: UK: University Hospital Department of Otolaryngology, Dundee \\
Setting of recruitment and treatment: 64 consecutive patients referred by their General Practitioners \\
Sample size: \\
- Number randomised: 61 \\
- Number completed: 56 \\
Participant (baseline) characteristics: \\
- Age: mean (range): 67.9 (40 to 83 ) years \\
- Gender: 31 males, 25 females \\
- Main diagnosis: bilateral hearing impairment \\
Other important effect modifiers: \\
- Hearing loss status: bilateral hearing impairment of $>25 \mathrm{~dB}$ HL (average over $0.25 \mathrm{kHz}, 0.5 \mathrm{kHz}, 1 \mathrm{kHz}$, \\
- $2 \mathrm{kHz}, 4 \mathrm{kHz}$ and $8 \mathrm{kHz}$ ) on pure-tone audiometry \\
- Previous experience of hearing aid use: no previous hearing aid provision \\
- Cognitive impairment: not stated \\
- Visual impairment: not stated \\
- Presence of tinnitus: not excluded unless it was the primary symptom
\end{tabular}

Inclusion criteria: those with a bilateral hearing impairment of $>25 \mathrm{~dB} \mathrm{HL}$ (average over $0.25 \mathrm{kHz}, 0.5$ $\mathrm{kHz}, 1 \mathrm{kHz}, 2 \mathrm{kHz}, 4 \mathrm{kHz}$ and $8 \mathrm{kHz}$ ); no previous hearing aid provision

Exclusion criteria: external or middle ear disease; mental or physical disorder that would interfere with hearing aid use; primary complaint of tinnitus

- Visit 1: bilateral impressions

- Visit 2: 4 weeks later, randomised to 1 of 2 groups: monaural aid left $(n=18)$ or right $(n=19)$ and binaural aids $(n=19)$

- Visit 3: 10 weeks later, monaural aid changed to the other ear OR binaural aids with 1 aid randomly returned

- Visit 4: 10 weeks later, previous monaural aid user given binaural aids OR those initially with binaural aids changed the side of use of a monaural aid

- Visit 5: 10 weeks later, patient preference for aid use: binaural or monaural use and, if the latter, which ear

A standard range of NHS aids to match the ear's hearing were used in 59 of the 61 patients and commercial aids were used in 2 patients to match their hearing impairment. During the study 13 aids were made more powerful and 1 aid was made less powerful. Uncomfortable listening level and uncomfortable loudness levels (ULL) were used to guide the choice of hearing aid. No comments were made regarding the choice of ear moulds. 
Vaughan-Jones 1993 (Continued)

- Patient preference for bilateral versus unilateral aids

\section{Secondary outcomes}

- Usage of hearing aids - self-report of hours per day

\begin{tabular}{ll}
\hline Funding sources & No information provided \\
\hline Declarations of interest & No information provided \\
\hline Notes & - \\
\hline
\end{tabular}

\section{Risk of bias}

\begin{tabular}{lll}
\hline Bias & Authors' judgement & Support for judgement \\
\hline $\begin{array}{l}\text { Random sequence genera- } \\
\text { tion (selection bias) }\end{array}$ & Unclear risk & Method of randomisation not stated. Although the study stated that "patients \\
& were randomised into one of two groups", a 1:1: ratio was observed for bilater- \\
al, unilateral (right) and unilateral (left), effectively making this a 2:1 ratio for & unilateral versus bilateral. Therefore, there were twice as many patients start- \\
& ing with monaural aids and patients spent twice as long using monaural aids \\
& (over $2 \times 10$-week periods) compared to using binaural aids (1 x 10-week peri- \\
od). The patients initially allocated to binaural aids had spent 20 weeks using & monaural aids before being asked their preference. \\
& No baseline data were reported; we are unable to judge whether the variables \\
that might affect the outcomes were evenly distributed.
\end{tabular}

Allocation concealment $\quad$ Unclear risk $\quad$ No information on the method of allocation was reported
(selection bias)

\begin{tabular}{|c|c|c|}
\hline $\begin{array}{l}\text { Blinding of participants } \\
\text { and personnel (perfor- }\end{array}$ & High risk & $\begin{array}{l}\text { Quote: "... no patient initially chose binaural aiding despite the open offer" } \\
\text { during the initial fitting session }\end{array}$ \\
\hline
\end{tabular}

mance bias)

All outcomes

The paper did not provide details of the information that was given to patients at this session; it is unclear why all patients chose unilateral aids despite having no prior experience with hearing aids

There were also no details of how hearing aids were fitted: variations in this could affect performance

\begin{tabular}{|c|c|c|}
\hline $\begin{array}{l}\text { Blinding of outcome as- } \\
\text { sessment (detection bias) }\end{array}$ & High risk & Quote: "no patient initially chose binaural aiding despite the open offer" \\
\hline All outcomes & & $\begin{array}{l}\text { All outcomes were patient-reported and subjective. In addition, there seemed } \\
\text { to be a preference for monaural aids in all patients before the aids were fitted. }\end{array}$ \\
\hline
\end{tabular}

\begin{tabular}{|c|c|c|}
\hline $\begin{array}{l}\text { Incomplete outcome data } \\
\text { (attrition bias) }\end{array}$ & Low risk & $\begin{array}{l}92 \% \text { of participants ( } 56 \text { of } 61 \text { ) completed the study: low risk of bias due to the } \\
\text { low dropout rates }\end{array}$ \\
\hline
\end{tabular}

All outcomes

$92 \%$ of participants (56 of 61 ) completed the study: low risk of bias due to the

Selective reporting (re- Unclear risk Protocol not available for assessment

porting bias)

dB: decibels

ERS: Emotional Response to Hearing Loss

FAAF: Four Alternative Auditory Feature test

NHS: National Health Service (UK)

PTA: pure-tone average

SD: standard deviation

SHHI: Social Hearing Handicap Index 
Characteristics of excluded studies [ordered by study ID]

\begin{tabular}{ll}
\hline Study & Reason for exclusion \\
\hline Boymans 2011 & Design: book chapter; no additional information on data from RCTs \\
\hline Formby 2015 & $\begin{array}{l}\text { Intervention: } 2 \times 2 \text { design comparing sound generators versus control and counselling versus no } \\
\text { counselling }\end{array}$ \\
\hline Gelfand 1987 & Study design: not a RCT; compared with non-randomised baseline data \\
\hline Kreisman 2010 & Intervention: all participants had binaural aids; compared different types of hearing aid designs \\
\hline Lavie 2014 & $\begin{array}{l}\text { Intervention: compared } 3 \text { strategies for fitting binaural aids (simultaneous versus sequential (start- } \\
\text { ing with right ear) versus sequential (starting with right ear)) }\end{array}$ \\
\hline McArdle 2012 & Study design: not a RCT; repeated measures design \\
\hline Metselaar 2009 & Intervention: compared a "comparative" versus a "prescriptive" approach for fitting hearing aids \\
\hline Silman 1984 & Study design: not a RCT; compared with non-randomised baseline data \\
\hline Yueh 2001 & Intervention: compared 3 different types of hearing aids against no amplification \\
\hline
\end{tabular}

$\mathrm{RCT}$ : randomised controlled trial

\section{APPENDICES}

\section{Appendix 1. Search strategies}

\begin{tabular}{|c|c|c|}
\hline MEDLINE (Ovid) & Embase (Ovid) & CRSO \\
\hline 1 exp Hearing Loss/ & 1 exp *hearing impairment/ & $\begin{array}{l}\text { \#1 MESH DESCRIPTOR } \\
\text { Hearing LoSS EXPLODE }\end{array}$ \\
\hline 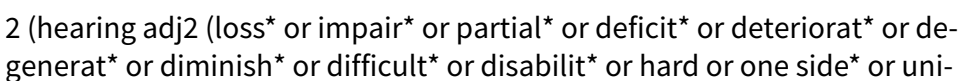 & $\begin{array}{l}2 \text { (hearing adj2 (loss* or im- } \\
\text { pair }^{\star} \text { or partial }{ }^{\star} \text { or deficit* }\end{array}$ & ALL TREES \\
\hline lateral)).ti,ab. & & \#2 ((hearing ADJ2 (loss* \\
\hline 3 deaf $^{\star} . t i, a b$. & or disabilit* or hard or one & deficit* $^{\star}$ or deteriorat ${ }^{\star}$ or \\
\hline 4 (hypoacus ${ }^{\star}$ or presbycus ${ }^{\star}$ or presbyacus ${ }^{\star}$ or sociocus ${ }^{\star}$ or nosocus ${ }^{\star}$ or & side* or unilateral)).ti,ab. & $\begin{array}{l}\text { degenerat }{ }^{\star} \text { or diminish* } \\
\text { or difficult* }{ }^{\star} \text { or disabilit* }\end{array}$ \\
\hline anacus $\left.{ }^{\star}\right) \cdot \mathrm{ti}, \mathrm{ab}$ & 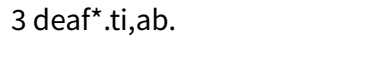 & or hard or one side* or \\
\hline 5 Persons With Hearing Impairments/ & 4 (hypoacus* or presbycus* & unilateral())):TI,AB,KY \\
\hline 6 or/1-5 & $\begin{array}{l}\text { or presbyacus }{ }^{\star} \text { or socio- } \\
\text { cus }^{\star} \text { or nosocus }\end{array}$ & $\begin{array}{l}\# 3 \text { ((hypoacus }{ }^{\star} \text { or } \\
\text { presbycus }{ }^{\star} \text { or pres- }\end{array}$ \\
\hline 7 letter/ & cus $\left.^{\star}\right) . t i, a b$. & byacus* or sociocus* \\
\hline 8 editorial/ & 5 or $/ 1-4$ & $\begin{array}{l}\text { or nosocus* or ana- } \\
\left.\left.\text { (us }^{\star}\right)\right): \mathrm{TI}, \mathrm{AB}, \mathrm{KY}\end{array}$ \\
\hline 9 news/ & 6 letter.pt. or letter/ & \#4 deaf*:TI,AB,KY \\
\hline \multirow[t]{2}{*}{10 exp historical article/ } & 7 note.pt. & \\
\hline & 8 editorial.pt & \\
\hline
\end{tabular}


(Continued)

11 Anecdotes as Topic/

12 comment/

13 case report/

14 (letter or comment $^{\star}$ ).ti.

15 or/ $7-14$

16 randomized controlled trial/ or random *.ti,ab.

1715 not 16

18 animals/ not humans/

19 Animals, Laboratory/

20 exp animal experiment/

21 exp animal model/

22 exp Rodentia/

23 (rat or rats or mouse or mice).ti.

24 or/17-23

256 not 24

26 Hearing Aids/

27 "Correction of Hearing Impairment"/is [Instrumentation]

28 (hearing adj (aid* or instrument $\left.{ }^{\star}\right)$ ).ti,ab.

29 (ear mold* or earmold* or ear mould* or earmould* or amplif*).ti,ab.

30 or/26-29

31 (contralateral or bilateral* or binaural or unilateral ${ }^{\star}$ or monoaural or (bi adj3 lateral $^{\star}$ ) or (uni adj3 lateral ${ }^{\star}$ ) or bimodal).ti,ab.

32 ((both or two or one or left or right or single or double) adj3 (side* or ear or ears or fitting $\left.\left.{ }^{\star}\right)\right)$.ti,ab.

3331 or 32

3430 and 33

35 ((both or two or one or left or right or single or double) adj3 (aid* or instrument $\left.\left.{ }^{\star}\right)\right) \cdot$ ti,ab.

\section{4 or 35}

\section{5 and 36}

38 randomized controlled trial.pt.

39 controlled clinical trial.pt.

40 randomized.ab.

41 placebo.ab.

42 drug therapy.fs.
9 case report/ or case study/

10 (letter or comment ${ }^{\star}$ ).ti.

11 or/6-10

12 randomized controlled trial/ or random*.ti,ab.

1311 not 12

14 animals/ not humans/

15 nonhuman/

16 exp animal experiment/

17 exp Experimental Animal/

18 animal model/

19 exp Rodent/

20 (rat or rats or mouse or mice).ti.

21 or/13-20

225 not 21

23 Hearing Aid/

24 (hearing adj (aid* or instrument $\left.\left.^{\star}\right)\right)$.ti,ab.

25 (ear mold* or earmold* or ear mould* or earmould ${ }^{\star}$ or amplif*).ti,ab.

\section{6 or/23-25}

27 (contralateral or bilateral $^{*}$ or binaural or unilateral* or monoaural or (bi adj3 lateral $^{\star}$ ) or (uni adj3 lateral ${ }^{\star}$ ) or bimodal).ti,ab.

28 ((both or two or one or left or right or single or double) adj3 (side* or ear or ears or fitting*)).ti,ab.

2927 or 28

3026 and 29

31 ((both or two or one or left or right or single or double) adj3 (aid* or instrumen$\left.\left.t^{\star}\right)\right)$.ti,ab.

3230 or 31

3322 and 32
\#5 MESH DESCRIPTOR Persons With Hearing Impairments

\#6 \#1 OR \#2 OR \#3 OR \#4 OR \#5

\#7 MESH DESCRIPTOR Heating Aids

\#8 MESH DESCRIPTOR

Correction of Hearing Impairment EXPLODE ALL TREES WITH QUALIFIERS IS

\#9 ((hearing next (aid* or instrumen$\left.\left.\left.t^{\star}\right)\right)\right): T I, A B, K Y$

\#10 ((ear next mold* or earmold* or ear next mould* or earmould* or amplif $\left.\left.^{\star}\right)\right): T I, A B, K Y$

\#11 \#7 OR \#8 OR \#9 OR \#10

\#12 ((contralateral or bilateral* or binaural or unilateral ${ }^{*}$ or monoaural or (bi ADJ3 lateral*) or (uni ADJ3 lateral ${ }^{\star}$ ) or bimodal)):TI,AB,KY

\#13 ((both or two or one or left or right or single or double) ADJ3 (side* or ear or ears or fitting $\left.{ }^{\star}\right)$ ):TI,AB, KY

\#14 \#12 OR \#13

\#15 \#11 AND \#14

\#16 (()both or two or one or left or right or single or double) ADJ3 (aid* or instrumen$\left.\left.\left.\mathrm{t}^{\star}\right)\right)\right): \mathrm{TI}, \mathrm{AB}, \mathrm{KY}$

\#17 \#15 OR \#16

\#18 \#6 AND \#17

43 randomly.ab.

Bilateral versus unilateral hearing aids for bilateral hearing impairment in adults (Review) 
(Continued)

44 trial.ab.

45 groups.ab.

4638 or 39 or 40 or 41 or 42 or 43 or 44 or 45

47 exp animals/ not humans.sh.

4846 not 47

4937 and 47
34 random* $^{\star}$ ti,ab.

35 factorial $^{\star}$.ti,ab.

36 (crossover ${ }^{\star}$ or cross

over $\left.^{\star}\right)$.ti,ab.

37 ((doubl ${ }^{\star}$ or singl $\left.{ }^{\star}\right)$ adj blind $\left.^{\star}\right) \cdot$ ti,ab.

38 (assign * or allocat * or volunteer ${ }^{\star}$ or placebo*).ti,ab.

39 crossover procedure/

40 single blind procedure/

41 randomized controlled

trial/

42 double blind procedure/

43 or/34-42

4433 and 43

\section{CINAHL}

\section{S31 S16 AND S30}

Search modes - Boolean/Phrase

$\mathrm{S} 30 \mathrm{~S} 17$ or $\mathrm{S} 18$ or $\mathrm{S} 19$ or $\mathrm{S} 20$ or S21 or S22 or S23 or S24 or S25 or S26 or S27 or S28 or S29

\section{S29 TX rct}

Search modes - Boolean/Phrase

S28 (MH "Placebos")

Search modes - Boolean/Phrase

S27 (MH "Quantitative Studies")

Search modes - Boolean/Phrase

S26 (MH "Random Assignment")

Search modes - Boolean/Phrase

S25 (MH "Clinical Trials+")

Search modes - Boolean/Phrase

S24 TX versus or vs

Search modes - Boolean/Phrase

S23 TX phase AND TX ( three or III )

Search modes - Boolean/Phrase

S22 TX "control group"

\section{LILACS}

Controlled Clinical Trials:

TW:"hearing aid" OR

TW:"hearing aids" OR

TW:Audífonos OR TW:"Auxiliares de Audição"
Trials Registries

\section{ClinicalTrials.gov}

("hearing aid" OR "hearing aids") AND randomized

\section{ICTRP}

Title: hearing aids OR "hearing aid" 
(Continued)

Search modes - Boolean/Phrase

S21 TX "treatment arm"

Search modes - Boolean/Phrase

S20 TX ( blind* or mask* ) AND TX ( single or double or triple or treble )

Search modes - Boolean/Phrase

S19 TX trial AND TX ( control* or comparative )

Search modes - Boolean/Phrase

S18 TX "cross over"

Search modes - Boolean/Phrase

S17 TX random * or factorial ${ }^{*}$ or placebo* or assign * or allocat* or cossover*

Search modes - Boolean/Phrase

S16 S5 AND S15

Search modes - Boolean/Phrase

S15 S13 OR S14

Search modes - Boolean/Phrase

S14 TX ((both or two or one or left or right or single or double) N3 (aid* or instrument $\left.{ }^{\star}\right)$ )

Search modes - Boolean/Phrase

S13 S9 AND S12

Search modes - Boolean/Phrase

S12 S10 OR S11

Search modes - Boolean/Phrase

S11 TX ((both or two or one or left or right or single or double) N3 (side* or ear or ears or fitting $\left.{ }^{\star}\right)$ )

Search modes - Boolean/Phrase

S10 TX (contralateral or bilateral ${ }^{\star}$ or binaural or unilateral ${ }^{\star}$ or monoaural or (bi N3 lateral ${ }^{\star}$ ) or (uni N3 lateral ${ }^{\star}$ ) or bimodal)

Search modes - Boolean/Phrase

\section{S9 S6 OR S7 OR S8}

Search modes - Boolean/Phrase

S8 TX (ear N3 mold $^{\star}$ or earmold* or (ear N3 mould*) or earmould* or amplif* $^{*}$

Search modes - Boolean/Phrase

S7 TX (hearing N3 (aid* or instrument ${ }^{\star}$ )

Search modes - Boolean/Phrase 
(Continued)

S6 (MH "Hearing Aids")

Search modes - Boolean/Phrase

\section{S5 S1 OR S2 OR S3 OR S4}

Search modes - Boolean/Phrase

S4 TX hypoacus* or presbycus* or presbyacus* or sociocus* or nosocus* or anacus*

Search modes - Boolean/Phrase

\section{S3 TX deaf*}

Search modes - Boolean/Phrase

S2 TX (hearing N2 (loss ${ }^{\star}$ or impair* or partial ${ }^{\star}$ or deficit* or deteriorat* or degenerat* ${ }^{\star}$ or diminish* or difficult* or disabilit* or hard or one side* or unilateral))

Search modes - Boolean/Phrase

S1 (MH "Hearing Disorders") OR (MH "Deafness") OR (MH "Hearing Loss, Partial+") OR (MH "Hyperacusis")

Search modes - Boolean/Phrase

\section{Appendix 2. Data extraction form}

\begin{tabular}{ll}
\hline REF ID: & Study title: \\
\hline Date of extraction: & Extracted by: \\
\hline
\end{tabular}

General comments/notes (internal for discussion):

FLOW CHART OF TRIAL:

$\begin{array}{ll}\text { Group A } & \text { Group B } \\ \text { (Intervention) } & \text { (Comparison) }\end{array}$

No. of people screened

No. of participants randomised - all

No. randomised to each group

No. receiving treatment as allocated 
(Continued)

No. not receiving treatment as allocated

- Reason 1

- Reason 2

No. dropped out

(no available follow-up data for any outcome)

No. excluded from analysis ${ }^{1}$ (for all outcomes)

- Reason 1

- Reason 2

1This should be the people who received the treatment and were therefore not considered 'dropouts' but were excluded from all analyses (e.g. because the data could not be interpreted or the outcome was not recorded for some reason).

Information to go into the 'Characteristics of included studies' table:

\begin{tabular}{ll} 
Methods & $\begin{array}{l}\text { Xarm, double/single/non-blinded, [multicentre] parallel-group/ } \\
\text { ration of treatment and } x \text { duration of follow-up }\end{array}$ \\
\hline Larticipants & Location: country, no. of sites etc. \\
Setting of recruitment and treatment: \\
Sample size: \\
- Number randomised: $x$ in intervention, y in comparison \\
- Number completed: $x$ in intervention, y in comparison \\
Participant (baseline) characteristics: \\
- Age: \\
- Gender: \\
- Main diagnosis: [as stated in paper] \\
Other important effect modifiers: \\
- Hearing loss status: \\
- Degree of asymmetry: \\
Inclusion criteria: \\
Exclusion criteria:
\end{tabular}

Interventions

Intervention $(\mathbf{n}=\mathbf{x})$ : (hearing aid name, type of hearing aid, how this was fitted, hearing aid style, whether volume control is allowed)

Comparator group $(\mathbf{n}=\mathbf{y})$ :

Use of additional interventions (common to both treatment arms):

Outcomes $^{1} \quad$ Outcomes of interest in this review:

\section{Hearing-specific health-related quality of life}


- Hearing Handicap Inventory for the Elderly (HHIE) or HHI for Adults (HHIA)

- Quantified Denver Scale of Communication (QDS)

- Auditory Disability Preference - Visual Analogue Scale (ADPI-VAS)

- Device Orientated Subjective Outcome Scale

- Any questionnaire not specified above that is relevant

2. Listening ability

- Abbreviated Profile of Hearing Aid Benefit (APHAB)

- Speech, Spatial and Qualities of Hearing (SSQ)

- Glasgow Hearing Aid Benefit Profile (GHABP) disability subscale

- Any questionnaire not specified above that is relevant

3. Adverse effects: pain, infection, etc.

\section{Patient preference}

Secondary outcomes/important outcomes:

\section{Outcomes reported by carer or 'communication partner' [add information on how this was} measured]

6. Usage of hearing aids [add information on how this was measured]

7. Health-related quality of life (generic scale)

- Health Utilities Index Mark 3 (HUI-3)

- EQ-5D

- SF-36

- Glasgow Benefit Inventory (GBI)

- WHO Disability Assessment Schedule (WHO-DAS)

- Self-Evaluation of Life Function (SELF)

- Any questionnaire mot specified above that is relevant

\section{Annoyance scale in patient-reported outcome measures [add information on how this was} measured]

9. Sound localisation as measured by laboratory tests [add information on how this was measured]

10. Speech in noise detection as measured by laboratory tests [add information on how this was measured]

Funding sources

Declarations of interest
"No information provided"/"None declared"/State source of funding

"No information provided"/"None declared"/State conflict

\section{Notes}

1DELETE all the outcomes that have not been reported in the study, leaving behind only the outcomes that are reported by the study. FINDINGS OF STUDY 


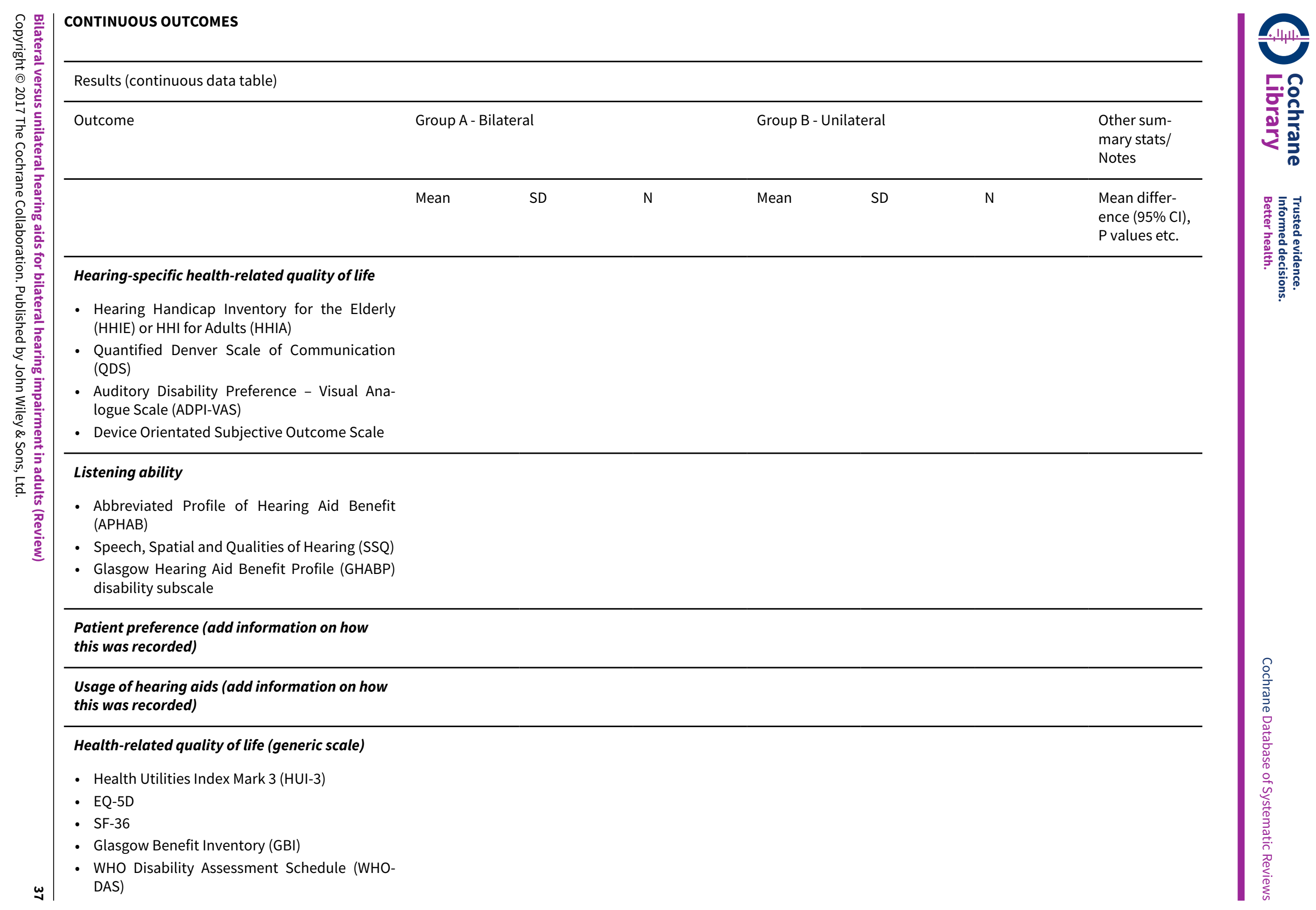




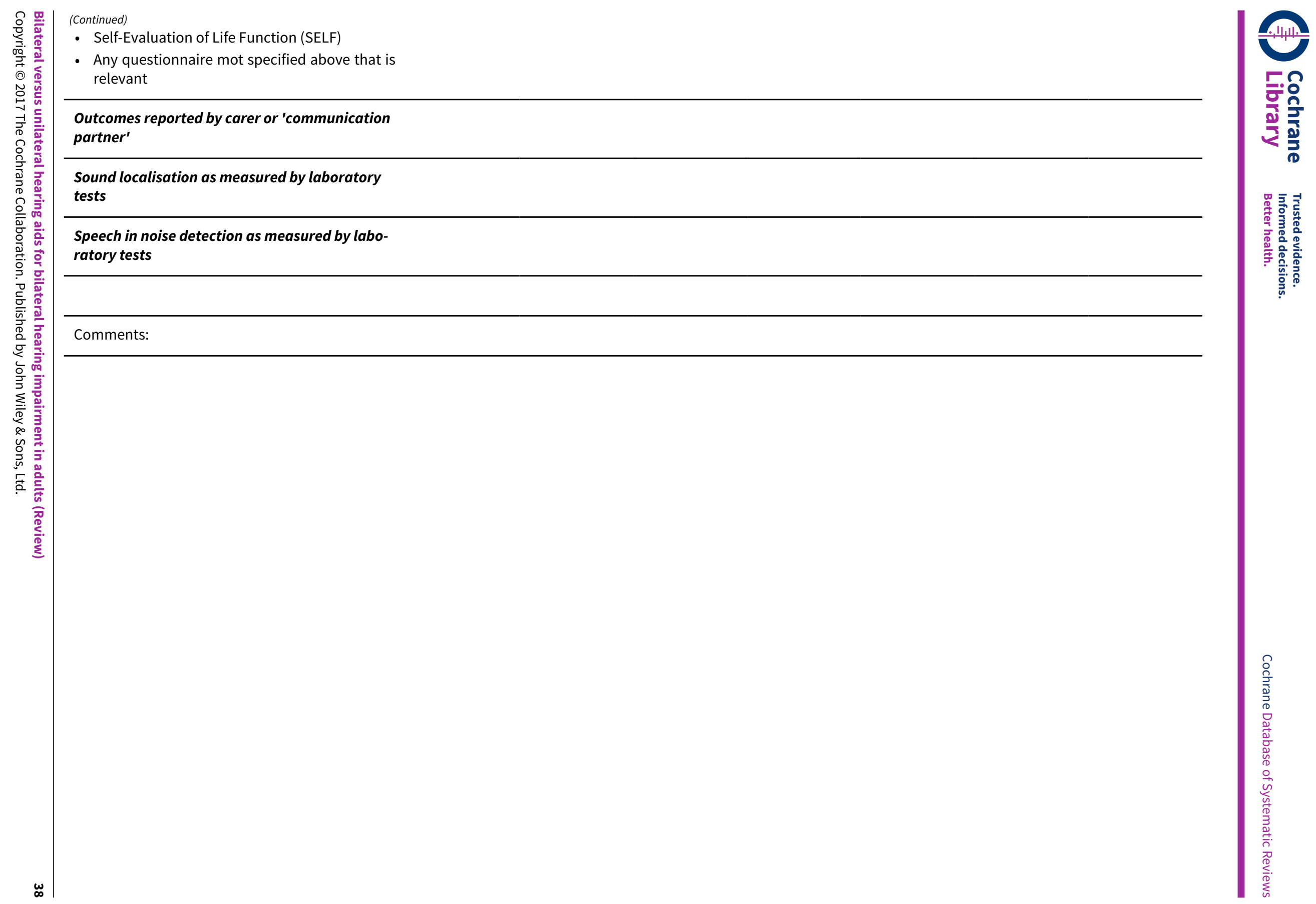




\title{
Appendix 3. 'Risk of bias' table template
}

\begin{tabular}{lll}
\hline Bias & Authors' judgement & Support for judgement \\
\hline Random sequence generation (selection bias) & High/unclear/low risk & Quote: \\
& & Comment: \\
\hline Allocation concealment (selection bias) & High/unclear/low risk & Comment: \\
\hline Blinding of participants and personnel (performance bias) & High/unclear/low risk & Quote: \\
& & Comment: \\
\hline Blinding of outcome assessment (detection bias) & High/unclear/low risk & Quote: \\
\hline
\end{tabular}

Incomplete outcome data (attrition bias)

Selective reporting (reporting bias)
High/unclear/low risk

Quote:

Comment:
High/unclear/low risk

Quote:

Comment:

Quote:

Comment:

Quote:

Comment:

\begin{abstract}
* The data collection form included specific items on the validity of outcome measures and "other biases" to ensure that all potential issues were extracted by the review authors. However, we did not find any specific issues that required this row, which were not already covered by the other domains. We did therefore not use this in the final review.
\end{abstract}

\section{CONTRIBUTIONS OF AUTHORS}

Anne GM Schilder: provided a clinical perspective throughout the review process; reviewed, edited and wrote the final review.

Lee Yee Chong: provided a methodological perspective, wrote the protocol, screened abstracts, extracted data and analysed data. Contributed to the write up of the review.

Saoussen Ftouh: provided a methodological perspective, wrote the protocol, screened abstracts, extracted data and analysed data. Contributed to the write up of the review.

Martin Burton: provided a clinical perspective throughout the review process; reviewed, edited and wrote the final review.

\section{DECLARATIONS OF INTEREST}

Anne GM Schilder: Professor Anne Schilder is joint Co-ordinating Editor of Cochrane ENT, but had no role in the editorial sign-off process for this review. Her evidENT team at UCL is supported by her NIHR Research Professorship award with the remit to develop a UK infrastructure and programme of clinical research in ENT, Hearing and Balance. Her institution has received a grant from GSK for a study on the microbiology of acute tympanostomy tube otorrhoea.

Lee Yee Chong: none known. 
Saoussen Ftouh: none known.

Martin Burton: Professor Martin Burton is joint Co-ordinating Editor of Cochrane ENT, but had no role in the editorial sign-off process for this review.

\section{SOURCES OF SUPPORT}

\section{Internal sources}

- No sources of support supplied

\section{External sources}

- National Institute for Health Research, UK.

Infrastructure funding for Cochrane ENT

\section{DIFFERENCES BETWEEN PROTOCOL AND REVIEW}

In the protocol for this review, we had specified that the 'speech in noise' and 'sound localisation' outcomes should be measured using laboratory methods. We found no study measuring and reporting these outcomes, however data from non-validated questionnaires were available. These data were considered by NICE committee members to be potentially useful in the absence of other data and were therefore included in the review and 'Summary of findings' table. Similarly, we had not planned to record the reasons provided by participants to support their preferences or choice, but we have recorded and reported this information.

We have also removed two exclusion criteria for participants: "active external or middle ear disease" and "previous experience of using a hearing aid". This reflects how the review was actually conducted; no exclusions would have been applied due to the scarcity of the evidence in this area. Instead, if any studies had included a significant number of non-first time hearing aid users, we would still have included them and then investigated this using subgroup analysis and considered it a factor for downgrading for indirectness of evidence. It is unlikely that any studies would have included a majority of patients with active external or middle ear disease.

'Audiometric benefit' was originally planned for presentation in the 'Summary of findings' table; this outcome is omitted from the table due to lack of data, to align the review with the NICE evidence review and to reduce the number of outcomes shown.

We used our data extraction forms to record 'other potential risks of bias' and 'risk of bias due to insensitive/non-validated instruments' to ensure that all possible risk of bias factors were extracted. However, we found that not all possible biases were adequately captured within the standard domains of the 'Risk of bias' tool and we therefore did not utilise these two additional domains.

We adapted the search strategy, making the following changes to the RCT filter for MEDLINE:

\begin{tabular}{ll}
\hline Protocol version & Final (review) version \\
\hline 38 randomized controlled trial.pt. & 38 randomized controlled trial.pt. \\
39 controlled clinical trial.pt. & 39 controlled clinical trial.pt. \\
40 randomi\#ed.ti,ab. & 40 randomized.ab. \\
41 placebo.ab. & 41 placebo.ab. \\
42 randomly.ti,ab. & 42 drug therapy.fs. \\
43 Clinical Trials as topic.sh. & 43 randomly.ab. \\
44 trial.ti & 44 trial.ab. \\
45 or/38-44 & 45 groups.ab. \\
4637 and 45 & 4638 or 39 or 40 or 41 or 42 or 43 or 44 or 45 \\
& 47 exp animals/ not humans.sh. \\
& 4846 not 47
\end{tabular}


We also added a supplementary search: "forward citation searches using Web of Knowledge, Web of Science (1945 to 8 June 2017 ) for papers citing Cox 2011 and Stephens 1991". We made these changes because two known studies were missed by the first search. We therefore adapted and re-ran the search strategy.

In Types of outcome measures we changed "Adverse effects (pain, infection)" to "Adverse effects (pain or discomfort in the ear, initiation or exacerbation of middle or outer ear infection)" in order to further clarify the type of adverse events measured.

\section{IN DEX TERMS}

\section{Medical Subject Headings (MeSH)}

*Hearing Aids [statistics \& numerical data]; Correction of Hearing Impairment [instrumentation] [methods]; Cross-Over Studies; Hearing Loss, Bilateral [ ${ }^{\star}$ rehabilitation]; Patient Preference; Quality of Life; Randomized Controlled Trials as Topic; Sound Localization; Speech Intelligibility

\section{MeSH check words}

Adult; Aged; Aged, 80 and over; Female; Humans; Male; Middle Aged 